\title{
Intrinsic chemiluminescence production from the degradation of haloaromatic pollutants during environmentally-friendly advanced oxidation processes: Mechanism, structure-activity relationship and potential applications
}

\author{
Benzhan Zhu*, Chen Shen, Huiying Gao, Liya Zhu, Jie Shao, Li Mao* \\ State Key Laboratory of Environmental Chemistry and Ecotoxicology, Research Center for Eco-Environmental Sciences and University of \\ Chinese Academy of Sciences, Chinese Academy of Sciences, Beijing 100085, China
}

\section{A R T I C L E I N F O}

Article history:

Received 1 April 2017

Revised 5 June 2017

Accepted 29 June 2017

Available online 14 July 2017

Keywords:

Halogenated phenols

Halogenated quinoid intermediates

Semiquinone radical

Hydroxyl radicals

Fenton reaction

Chemiluminescene method

\begin{abstract}
A B S T R A C T
The ubiquitous distribution of halogenated aromatic compounds (XAr) coupled with their carcinogenicity has raised public concerns on their potential risks to both human health and the ecosystem. Recently, advanced oxidation processes (AOPs) have been considered as an "environmentally-friendly" technology for the remediation and destruction of such recalcitrant and highly toxic XAr. During our study on the mechanism of metal-independent production of hydroxyl radicals $(. \mathrm{OH})$ by halogenated quinones and $\mathrm{H}_{2} \mathrm{O}_{2}$, we found, unexpectedly, that an unprecedented .OH-dependent two-step intrinsic chemiluminescene (CL) can be produced by $\mathrm{H}_{2} \mathrm{O}_{2}$ and tetrachloro-p-benzoquinone, the major carcinogenic metabolite of the widely used wood preservative pentachlorophenol. Further investigations showed that, in all .OH-generating systems, CL can also be produced not only by pentachlorophenol and all other halogenated phenols, but also by all XAr tested. A systematic structure-activity relationship study for all 19 chlorophenolic congeners showed that the CL increased with an increasing number of $\mathrm{Cl}$-substitution in general. More importantly, a relatively good correlation was observed between the formation of quinoid/semiquinone radical intermediates and CL generation. Based on these results, we propose that .OH-dependent formation of quinoid intermediates and electronically excited carbonyl species is responsible for this unusual CL production; and a rapid, sensitive, simple, and effective CL method was developed not only to detect and quantify trace amount of $\mathrm{XAr}$, but also to provide useful information for predicting the toxicity or monitoring real-time degradation kinetics of XAr. These findings may have broad chemical, environmental and biological implications for future studies on halogenated aromatic persistent organic pollutants. (c) 2017 The Research Center for Eco-Environmental Sciences, Chinese Academy of Sciences.
\end{abstract} Published by Elsevier B.V.

\section{Introduction}

Halogenated aromatic compounds (XAr) have been widely used as pesticides, herbicides, wood preservatives, personal care agents, pharmaceuticals, flame retardants, and many other industrial products (Zhu and Shan, 2009; Zhu et al., 2011a; Dann and Hontela, 2010; De Wit, 2002). Most of these compounds are poorly biodegradable both in water and soil, which makes them persistent and widely distributed in the environment, and have earned them the name persistent organic pollutants (POPs)

\footnotetext{
* Corresponding author. E-mails: bzhu@rcees.ac.cn (Benzhan Zhu), limao@rcees.ac.cn (Li Mao).
} 
from UNEP (United Nations Environment Program) (Zhu and Shan, 2009; Zhu et al., 2011a; Dann and Hontela, 2010; De Wit, 2002). The ubiquitous distribution of these recalcitrant and highly toxic XAr coupled with their carcinogenicity has raised public concerns on their potential risks to both human health and the ecosystem (Dann and Hontela, 2010; De Wit, 2002; Ramamoorthy, 1997; Fang et al., 2000; Zimbron and Reardon, 2009; Lan et al., 2008; Gupta et al., 2002; Sorokin et al., 1995; Zhang and Huang, 2003; Zhong et al., 2012; Peller et al., 2003). Polyhalogenated phenols are an important class of XAr, and some of them, such as the widely used wood preservative pentachlorophenol (PCP) and 2,4,6-trichlorophenol (2,4,6-TCP), have been listed by the U.S. Environmental Protection Agency (EPA) as priority pollutants. Recently, PCP has been classified as a group I human carcinogen by the International Agency for Research on Cancer (IARC Working Group, 2016).

Among all the techniques used or tested so far, advanced oxidation processes (AOPs) have been increasingly favored as an "environmentally-friendly" technology for treating recalcitrant chlorinated phenols (CPs) and other XAr in the remediation of contaminated water or soil (Von Sonntag, 2008; Wang and Xu, 2012; Pera-Titus et al., 2004). Several alternative techniques have been well established for the oxidation and degradation of CPs and XAr, such as Fenton and Fenton-like oxidation (Zimbron and Reardon, 2009; Liou et al., 2004; Liao et al., 2007), ultra-violet (UV)-photolysis (Lente and Espenson, 2003; Chu, 1999), and ozonation (Hong and Zeng, 2002), during which the recalcitrant XAr were degraded or even mineralized. In those "environmentally-green" AOP systems, which are based on hydrogen peroxide (Fenton and Fenton-like reactions) and ozone $\left(\mathrm{O}_{3}, \mathrm{O}_{3} / \mathrm{H}_{2} \mathrm{O}_{2}\right)$, the most reactive radical intermediate formed is the hydroxyl radical (Von Sonntag, 2008).

Chemiluminescence (CL) is a phenomenon in which molecules in a chemically generated excited state liberate energy with light emission. CL frequently accompanies organic peroxide decomposition and free radical formation (Schuster, 1979; Matsumoto, 2004; Almeida de Oliveira et al., 2012; Widder, 2010; Adam et al., 2005). Since the CL intensity is governed by the rate of the chemical reaction, it can be used to quantify any analyte whose concentration is rate-determining (Grayeski, 1987). CL intensity-based analytical assays are inherently highly sensitive, rapid, and simple to operate, without requiring pre-treatment of samples. Therefore, they are being increasingly used as a sensitive analytical method in various research fields (Grayeski, 1987; McCapra, 2000). For example, the reactive oxygen species (ROS) generated during UV-irradiation of nano- $\mathrm{TiO}_{2}$ were selectively and sensitively detected by CL method (Wang et al., 2014); trace amount of transition metal ions such as ferrous(II) and cobalt(II) in estuarine and coastal waters could be quantitatively determined by a pyrogallol- $\mathrm{H}_{2} \mathrm{O}_{2}$ CL system (Cannizzaro et al., 2000); and a good molecular imprinting CL sensor could be designed to recognize and separate target molecules when combining the molecular imprinting with high-sensitivity CL method (Lin and Yamada, 2000).

The hydroxyl radical (.OH) is an extremely reactive ROS which is important in chemistry, biology, toxicology, medicine, atmospheric and environmental science (Zhu and Shan, 2009; Halliwell and Gutteridge, 2007; Wagner and Cadet, 2010; Xu and
Chance, 2007; Voinov et al., 2011; Montzka et al., 2011; Rohrer and Berresheim, 2006). In biology, . OH is considered as the most reactive and harmful ROS, which can cause deoxyribonucleic acid (DNA), protein, and lipid oxidation (Halliwell and Gutteridge, 2007; Wagner and Cadet, 2010; Xu and Chance, 2007). Many ailments such as cancer, arthritis, and Parkinson's disease are linked to .OH (Halliwell and Gutteridge, 2007). .OH is also important in environmental and atmospheric chemistry due to its ability to oxidize and destroy organic pollutants efficiently and has been called the atmosphere's "detergent" (Zhu and Shan, 2009; Gupta et al., 2002; Sorokin et al., 1995; Voinov et al., 2011; Montzka et al., 2011; Rohrer and Berresheim, 2006; Meunier, 2002). One of the most widely-accepted mechanisms for .OH production is through the transition metal-catalyzed Fenton or Fenton-like reactions (Zhu and Shan, 2009; Halliwell and Gutteridge, 2007; Wagner and Cadet, 2010; Xu and Chance, 2007). Recently, however, we found that .OH (alkoxyl and quinone-ketoxy radicals) can be produced by halogenated quinones and $\mathrm{H}_{2} \mathrm{O}_{2}$ (organic hydroperoxides) independent of transition metal ions, and a novel nucleophilic substitution coupled with homolytic decomposition reaction mechanism was proposed (Zhu et al., 2000, 2002, 2007a, 2007b, 2009, 2011b; Jia et al., 2010; Yin et al., 2013; Huang et al., 2013, 2015; Shao et al., 2013; Qin et al., 2013; Zhao et al., 2014). Interestingly, it was observed by a Japanese research group that, in the presence of fluorescent agent riboflavin, CL could be produced by $\mathrm{H}_{2} \mathrm{O}_{2}$ and brominated quinoid compounds isolated from acorn worm, a luminous marine organism (Kanakubo and Isobe, 2005). However, neither the underlying molecular mechanism for CL production, nor its possible correlation with. $\mathrm{OH}$ production is clear. Therefore, in a series of recent studies, we addressed the following questions: (1) Can CL be produced by halogenated quinones and $\mathrm{H}_{2} \mathrm{O}_{2}$ in the absence of a fluorescent agent; (2) If so, what are the molecular mechanisms underlying CL generation, and are there any correlations between . OH and CL production; (3) Whether the precursors of halogenated quinones, such as PCP and other XAr, demonstrate similar CL emission property during AOPs; (4) If so, what is the structure activity relationship (SAR) and its underlying molecular basis; and (5) What are the potential chemical, biological and environmental implications?

\section{An unprecedented .OH-dependent CL produc- tion by polyhalogenated quinones and $\mathrm{H}_{2} \mathrm{O}_{2}$}

\subsection{Tetrachloro-p-benzoquinone (P-TCBQ) and $\mathrm{H}_{2} \mathrm{O}_{2}$ can produce two-step CL}

P-TCBQ is one of the major genotoxic and carcinogenic quinoid metabolites of the widely used wood preservative PCP (Zhu and Shan, 2009). To our surprise, we found that, even in the absence of fluorescent agents, intrinsic CL could be produced by $P$-TCBQ and $\mathrm{H}_{2} \mathrm{O}_{2}$. In contrast, neither P-TCBQ nor $\mathrm{H}_{2} \mathrm{O}_{2}$ alone could produce any CL (Fig. 1A) ( $\mathrm{Zhu}$ et al., 2012). More interestingly, the CL produced by P-TCBQ and $\mathrm{H}_{2} \mathrm{O}_{2}$ was found to be an unusual two-step CL: the first one was strong but short-lived with the maximum light emission at band 490-535 nm, and the second one was weak but lasting longer with CL emission at band 535-555 nm (Fig. 1A and B). 

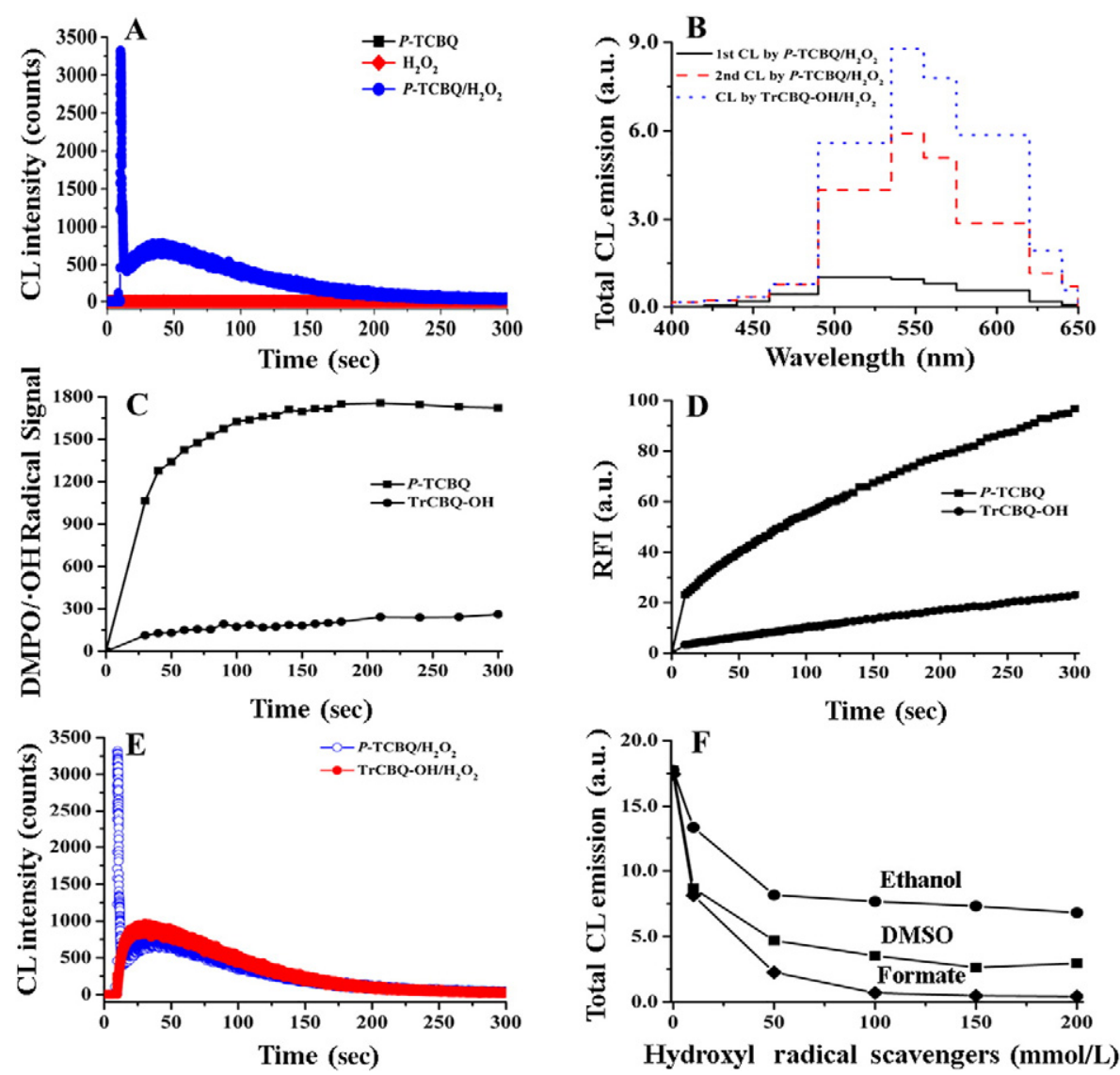

Fig. 1 - An unexpected two-step intrinsic .OH-dependent CL could be produced by P-TCBQ and $\mathrm{H}_{2} \mathrm{O}_{2}$ (modified on ref. ( $\mathrm{Zhu}$ et al., 2012)). (A) Two-step CL could be produced by P-TCBQ and $\mathrm{H}_{2} \mathrm{O}_{2}$; (B) The CL spectra produced by $\mathrm{P}-\mathrm{TCBQ} / \mathrm{H}_{2} \mathrm{O}_{2} ;(C)$ and (D) The ESR and fluorescent kinetic study on. $\mathrm{OH}$ production by $\mathrm{P}-\mathrm{TCBQ} / \mathrm{H}_{2} \mathrm{O}_{2}$. $(\mathrm{E})$ The second-step $\mathrm{CL}$ produced by $\mathrm{P}-\mathrm{TCBQ} / \mathrm{H}_{2} \mathrm{O}_{2}$ is the same as the $\mathrm{CL}$ by $\mathrm{TrCBQ}-\mathrm{OH} / \mathrm{H}_{2} \mathrm{O}_{2}$; (F) The CL production by $\mathrm{P}-\mathrm{TCBQ} / \mathrm{H}_{2} \mathrm{O}_{2}$ was quenched by the classic .OH scavengers. P-TCBQ, TrCBQ-OH, $0.1 \mathrm{mmol} / \mathrm{L} ; \mathrm{H}_{2} \mathrm{O}_{2}, 100 \mathrm{mmol} / \mathrm{L}$. For .OH detection in (C) and (D), by ESR method: 5,5-dimethyl-1-pyrroline $\mathrm{N}$-oxide (DMPO), $100 \mathrm{mmol} / \mathrm{L}$; by fluorescent method: coumarin-3-carboxylic acid (3-CCA), $4 \mathrm{mmol} / \mathrm{L}$. CL: chemiluminescence; P-TCBQ: tetrachloro-p-benzoquinone; TrCBQ: trichlorohydroxy-p-benzoquinone; ESR:electron spin resonance.

1.2. The two-step CL production from $\mathrm{P}-\mathrm{TCBQ} / \mathrm{H}_{2} \mathrm{O}_{2}$ was directly dependent on two-step. $\mathrm{OH}$ formation

It should be noted that, the reaction between P-TCBQ and $\mathrm{H}_{2} \mathrm{O}_{2}$ is a two-step process. In the presence of excess $\mathrm{H}_{2} \mathrm{O}_{2}, \mathrm{P}$-TCBQ was first converted to the initial transient mono-hydroxylation intermediate trichlorohydroxy-p-benzoquinone (TrCBQ-OH), and then further to the final dihydroxylation product 2,5dichloro-3,6-dihydroxyl-p-benzoquinone (DDBQ) (Zhu et al., 2012). Interestingly, during the two-step reaction process of P-TCBQ $/ \mathrm{H}_{2} \mathrm{O}_{2}$, two clear-cut phases of .OH production were also observed: the first phase is fast, while the second one is much slower (Fig. 1C and D). Further investigation revealed that the two-step .OH production correlates well with the two-step CL production by $\mathrm{P}-\mathrm{TCBQ} / \mathrm{H}_{2} \mathrm{O}_{2}: 1$ ) The time course and the emission spectrum of the second-step CL produced by $\mathrm{P}-\mathrm{TCBQ} / \mathrm{H}_{2} \mathrm{O}_{2}$ was almost the same as compared with the one produced by TrCBQ-OH/ $\mathrm{H}_{2} \mathrm{O}_{2}$ (Fig. 1B and E); and 2) . OH could also be produced by $\operatorname{TrCBQ}-\mathrm{OH} / \mathrm{H}_{2} \mathrm{O}_{2}$, which is much weaker and slower as compared with the first-step .OH production by $\mathrm{P}-\mathrm{TCBQ} / \mathrm{H}_{2} \mathrm{O}_{2}$ (Fig. 1C and D).

Interestingly, we found that the two-step CL production by P-TCBQ $/ \mathrm{H}_{2} \mathrm{O}_{2}$ was directly dependent on .OH formation, which was based on the following lines of evidence (Zhu et al., 2012): (1) The CL produced by $\mathrm{P}-\mathrm{TCBQ} / \mathrm{H}_{2} \mathrm{O}_{2}$ was markedly inhibited by several well-known .OH scavengers such as dimethyl sulfoxide (DMSO), formate and ethanol (Fig. $1 F)$, but could be further enhanced significantly by extra .OH produced by addition of the iron complex Fe(II)-EDTA (EDTA: ethylenediaminetetraacetic acid); (2) CL could be produced by P-TCBQ only with $\mathrm{H}_{2} \mathrm{O}_{2}$, but not with organic hydroperoxides such as tert-butyl hydroperoxide $(\mathrm{t}-\mathrm{BuOOH})$, which is consistent with the fact that .OH could be produced by P-TCBQ only with $\mathrm{H}_{2} \mathrm{O}_{2}$, but not with organic hydroperoxides (only alkoxyl radicals were produced in these cases); (3) CL could be produced by $\mathrm{H}_{2} \mathrm{O}_{2}$ not only with $\mathrm{P}$-TCBQ but also with all other halogenated quinones, but not with non- or methylsubstituted quinones.

1.3. Several ring-opening products were identified during the reaction between $\mathrm{P}-\mathrm{TCBQ}$ and $\mathrm{H}_{2} \mathrm{O}_{2}$

We found that, unexpectedly, beside above-mentioned dechlorinated and hydroxylated quinoid reaction products TrCBQ-OH and DDBQ several quinone ring-opening products were generated from the reaction between $P-T C B Q$ and $\mathrm{H}_{2} \mathrm{O}_{2}$, by 
complementary applications of multiple analytical methods (Zhu et al., 2012). The major ring-opening product was identified as dichloromaleic acid (DCMA), with chloromalonic acid (CMA) and oxalic acid as two minor ring-opening products. Furthermore, about $32.3 \%$ P-TCBQ were found to be converted to $\mathrm{CO}_{2}$ (and/or CO).

\subsection{Possible light-emitting species}

In our work, since the addition of fluorescent agents such as riboflavin or 9,10-diphenylanthracene (DPA) demonstrated no effect on CL production, indicating that the CL produced by $\mathrm{P}-\mathrm{TCBQ} / \mathrm{H}_{2} \mathrm{O}_{2}$ must be a direct or intrinsic one: some light-emitting species must be generated during the reaction of $\mathrm{P}$-TCBQ with $\mathrm{H}_{2} \mathrm{O}_{2}$. The fact that several ring-opening products that were formed during $P-\mathrm{TCBQ} / \mathrm{H}_{2} \mathrm{O}_{2}$ reaction also suggest that the process of ring-opening might be responsible for generating excited light-emitting species and the corresponding energy required for CL emission.

Dioxetanes (especially for 1,2-dioxetanes), which are a class of high energy four-membered-ring peroxides, have been proposed as the critical intermediate in many chemiluminescent reactions (Schuster, 1979; Matsumoto, 2004; Adam et al., 2005; Bos et al., 2009). We propose that an unusual quinone 1,2-dioxetane intermediate might be produced during the reaction between P-TCBQ and $\mathrm{H}_{2} \mathrm{O}_{2}$. The following thermal decomposition of quinone-1,2-dioxetane might generate electronically excited carbonyl-containing compound as light emitter which emits CL directly. Our preliminary thermo-chemical calculations suggested this maybe in the case, the energy released from the decomposition of the proposed quinone-1,2-dioxetane could reach up to $80.2 \mathrm{kcal} / \mathrm{mol}$, which is sufficient to meet the demand of CL emission of $P-T C B Q / \mathrm{H}_{2} \mathrm{O}_{2}$.

\subsection{Molecular mechanism of .OH-dependent CL production by} P-TCBQ and $\mathrm{H}_{2} \mathrm{O}_{2}$

On the basis of all the above results and our previous findings (Zhu and Shan, 2009; Zhu et al., 2002, 2007a, 2007b, 2009), a novel molecular mechanism was proposed for .OH-dependent CL production by $\mathrm{P}-\mathrm{TCBQ} / \mathrm{H}_{2} \mathrm{O}_{2}$ (Zhu et al., 2012) (Scheme 1): A nucleophilic reaction may take place between P-TCBQ and $\mathrm{H}_{2} \mathrm{O}_{2}$, forming a quinone-hydroperoxide reaction intermediate TrCBQ-OOH, which could decompose homolytically to produce . $\mathrm{OH}$ and the oxygen-centered enoxy radical TrCBQ-O.. TrCBQ-O. then could either disproportionate to form the initial transient intermediate $\operatorname{TrCBQ}-\mathrm{OH}$, or isomerize to form the carbon-centered ketoxy radical $. \operatorname{Tr} \mathrm{CBQ}=\mathrm{O}$, which could be attacked by .OH to form multi-carbonyl compound I. The unstable compound I may further react with $\mathrm{H}_{2} \mathrm{O}_{2}$ to form a quinone-1,2-dioxetane, which further decomposed to form the ring-opening excited light emitter $[\mathrm{A}]^{*}$. The first-step CL was emitted concurrently when electronically excited state of $[\mathrm{A}]^{*}$ returning to ground state of $[\mathrm{A}]$, and the subsequent decomposition of $[\mathrm{A}]$ leads to the formation of final products DCMA and $\mathrm{CO}_{2}$ (and/or $\mathrm{CO}$ ).

The second-step CL produced by $\mathrm{P}-\mathrm{TCBQ} / \mathrm{H}_{2} \mathrm{O}_{2}$ should be similar with the first-step CL emission. However, the secondstep CL exhibits the maximum emission at band $535-555 \mathrm{~nm}$ as compared to band $490-535 \mathrm{~nm}$ for the first-step CL (Fig. 1B). This

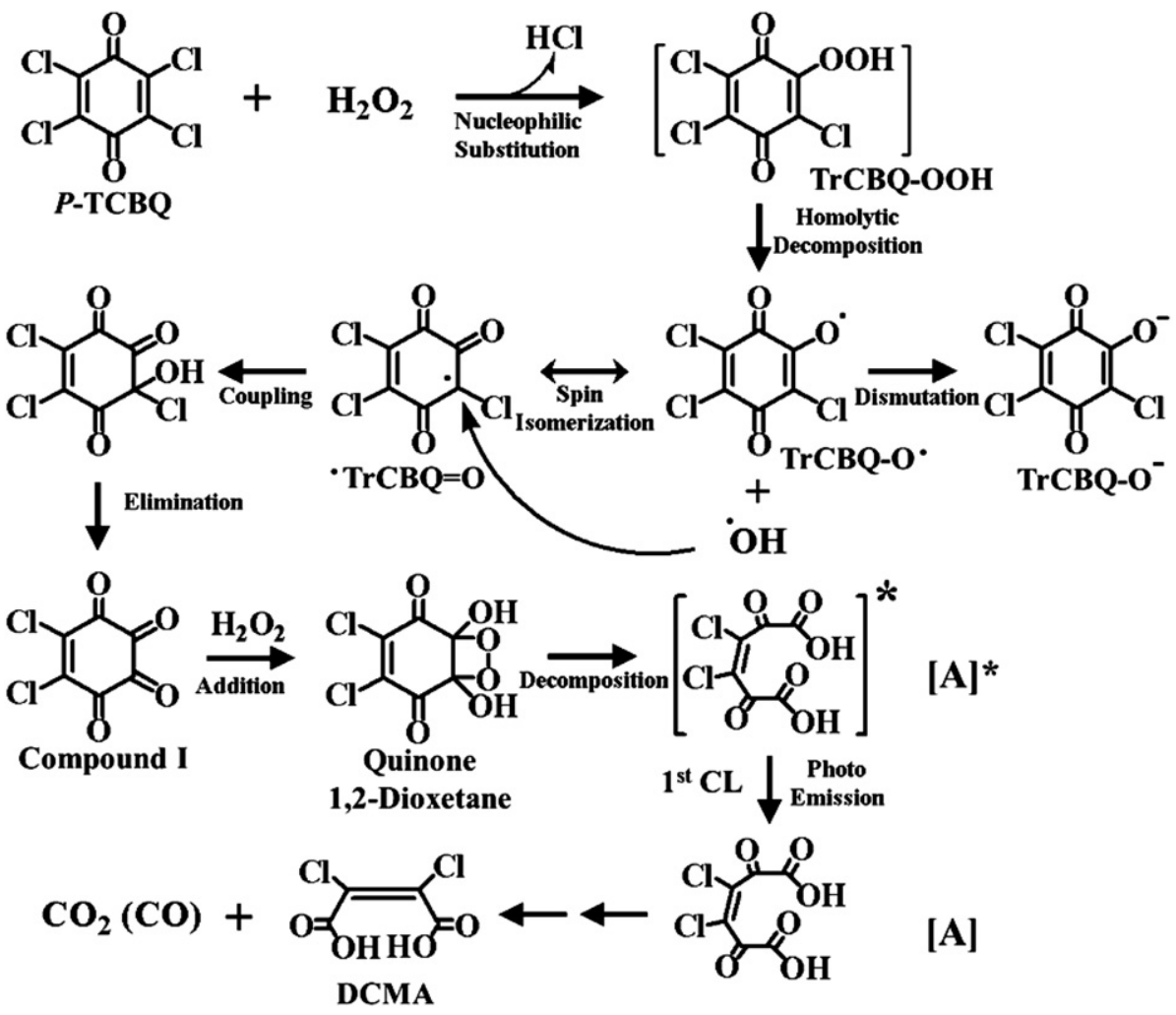

Scheme 1 - Proposed molecular mechanism for the .OH-dependent CL production by P-TCBQ and $\mathrm{H}_{2} \mathrm{O}_{2}$ (modified on ref. ( $\mathrm{Zhu}$ et al., 2012)). 
might be due to the fact that the light emitter in second-step CL has one more electron-donating hydroxyl group than the light emitter in first-step CL emission, which therefore caused the second-step CL to be red-shifted to longer wavelength (Zhu et al., 2012).

\section{Intrinsic CL production from degradation of the priority pollutant PCP during AOPs via .OH-dependent pathway}

2.1. An intrinsic CL emission could be produced during advanced oxidation of PCP by the classic .OH-generating Fenton system

It has been well known that the highly toxic PCP can be degraded to its quinoid intermediates such as P-TCBQ with the classic .OH-generating Fenton system (Zimbron and Reardon, 2009). As shown above, we found that the reaction between $\mathrm{H}_{2} \mathrm{O}_{2}$ and $P$-TCBQ could generate both . $\mathrm{OH}$ and CL emission. Therefore, it will be interesting to know under which conditions PCP can generate CL? Since there is no direct interaction between PCP and $\mathrm{H}_{2} \mathrm{O}_{2}$, therefore, as expected, neither . $\mathrm{OH}$, nor CL generation could be observed with $\mathrm{PCP} / \mathrm{H}_{2} \mathrm{O}_{2}$ (Fig. 2A). However, when the classic Fenton reagent (Fe(II)-EDTA) was added to $\mathrm{PCP} / \mathrm{H}_{2} \mathrm{O}_{2}$, a typical CL spectra with a broad band (510$580 \mathrm{~nm}$, centered at $535 \mathrm{~nm}$ ) could be observed (Fig. 2A, B). Interestingly, it has been observed by others that a weak CL could be also generated from Fenton reagent induced degradation of ortho-chlorophenol (Lin et al., 2012).

Similar to the case in $\mathrm{P}-\mathrm{TCBQ} / \mathrm{H}_{2} \mathrm{O}_{2}$ system, we found that the CL production by PCP/Fe(II)-EDTA/ $\mathrm{H}_{2} \mathrm{O}_{2}$ was also directly dependent on $\mathrm{OH}$ formation, as indicated by the following lines of evidence (Mao et al., 2015): (1) The CL produced by PCP/ $\mathrm{Fe}(\mathrm{II})-\mathrm{EDTA} / \mathrm{H}_{2} \mathrm{O}_{2}$ was markedly inhibited by several typical .OH scavengers (Fig. 2C); (2) Not only the CL emission and . $\mathrm{OH}$ generation could be markedly accelerated, but also the CL intensity and $\mathrm{OH}$ yield were enhanced significantly as the concentration of Fe(II)-EDTA and $\mathrm{H}_{2} \mathrm{O}_{2}$ was increased; (3) CL was also observed when Fe(II)-EDTA was substituted by two other well-known .OH-generating Fenton agents Fe(II)DTPA (diethylenetriaminepentaacetic acid) and Fe(II)-NTA (nitrilotriacetic acid) (Fig. 2D) (Wardman and Candeias, 1996; Goldstein et al., 1993); and (4) CL emission correlated strongly
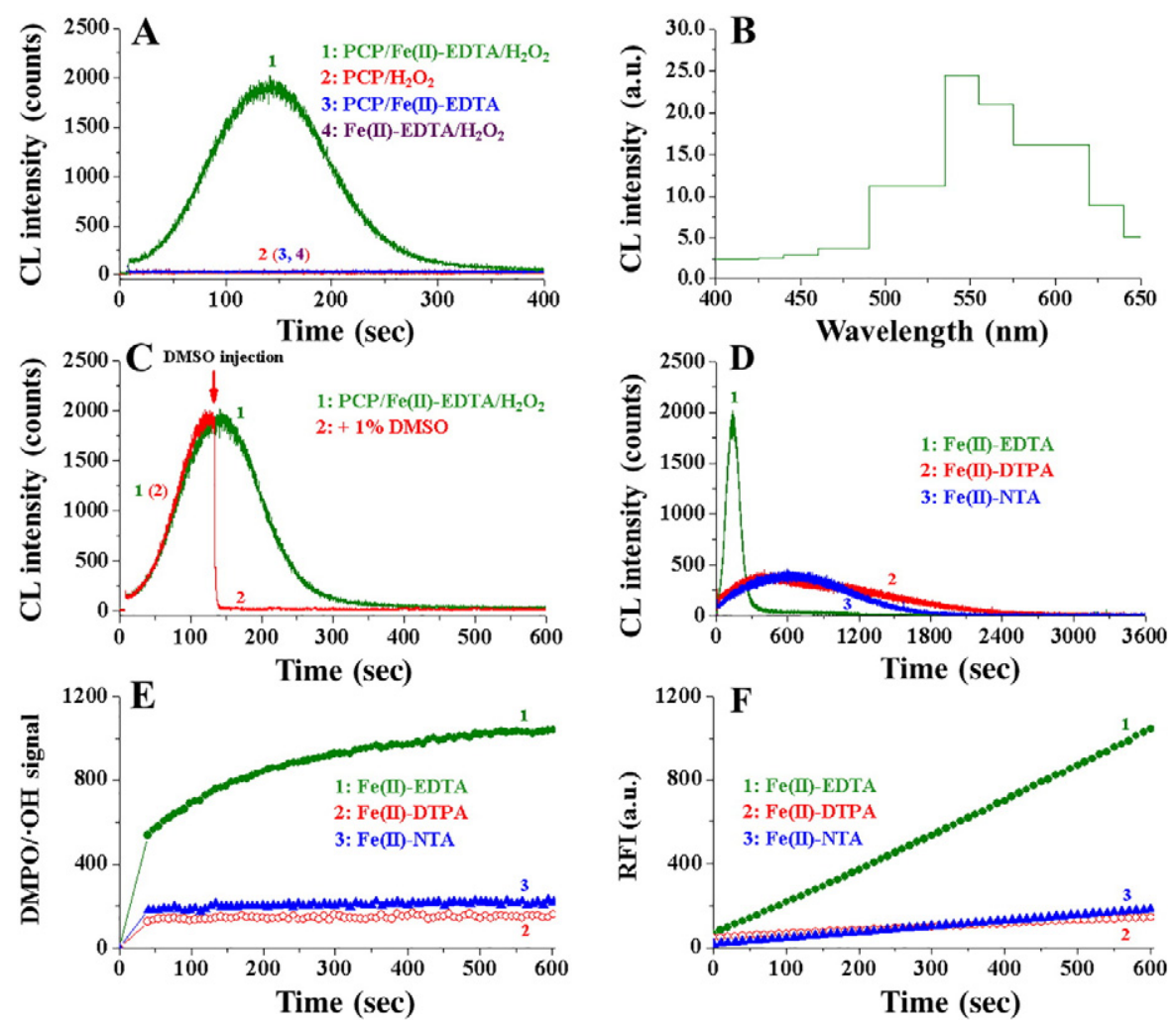

Fig. 2 - An intrinsic .OH-dependent CL emission could be produced during advanced oxidation of PCP by the classic .OH-generating Fenton system (modified on ref. (Mao et al., 2015)). (A) CL could be produced by PCP/Fe(II)-EDTA/ $\mathrm{H}_{2} \mathrm{O}_{2}$; (B) The emission spectrum of CL; (C) CL production from PCP/Fe(II)-EDTA/ $\mathrm{H}_{2} \mathrm{O}_{2}$ could be markedly quenched by the typical .OH scavenger DMSO; (D) CL production was also observed with two other well-known .OH-generating Fenton agents Fe(II)-DTPA and Fe(II)-NTA; (E) and (F): The ESR and fluorescent kinetic study on. $\mathrm{OH}$ generation by the three $\mathrm{Fe}(\mathrm{II})$ complexes and $\mathrm{H}_{2} \mathrm{O}_{2}$. PCP, $0.02 \mathrm{mmol} / \mathrm{L}$; Fe(II)-EDTA, Fe(II)-DPTA, $\mathrm{Fe}(\mathrm{II})-\mathrm{NTA}, 1 \mathrm{mmol} / \mathrm{L} ; \mathrm{H}_{2} \mathrm{O}_{2}, 100 \mathrm{mmol} / \mathrm{L}$. For .OH detection in (E) and (F), by ESR method: DMPO, $100 \mathrm{mmol} / \mathrm{L} ;$ by fluorescent method: 3-CCA, 4 mmol/L. PCP: pentachlorophenol; EDTA: ethylenediaminetetraacetic acid; DMSO: dimethyl sulfoxide; DTPA: diethylenetriaminepentaacetic acid; NTA: nitrilotriacetic acid; DMPO: 5,5-dimethyl-1-pyrroline N-oxide; 3-CCA: coumarin-3-carboxylic acid; ESR:electron spin resonance. 
with the rate of .OH generation from the three $\mathrm{Fe}$ (II) complexes and $\mathrm{H}_{2} \mathrm{O}_{2}$, as measured by both electron spin resonance (ESR) spin-trapping and fluorescent methods (Fig. 2E and F).

Analogous intrinsic CL and similar .OH-dependent behaviors were also observed when PCP was substituted with other pentahalogenated phenols, including pentabromophenol (PBP) and pentafluorophenol (PFP). These findings demonstrated that the .OH-dependent CL production is a general phenomenon between pentahalogenated phenols and classic.OH-generated Fenton system.

2.2. Chlorinated quinoid compounds and DCMA were identified as the respective transient intermediates and ring-opening product in $\mathrm{PCP} / \mathrm{Fe}$ (II)-EDTA/ $\mathrm{H}_{2} \mathrm{O}_{2}$ system

The above results suggest that, in the PCP/Fe(II)-EDTA $/ \mathrm{H}_{2} \mathrm{O}_{2}$ system, the primary species responsible for CL emission are probably transient intermediates or final products of PCP during its degradation by .OH. These may include the corresponding tetrachloroquinoid compounds, such as tetrachloro- $p$ hydroquinone (P-TCHQ), $\mathrm{P}-\mathrm{TCBQ}$ tetrachloro-o-hydroquinone (O-TCHQ), and tetrachloro-o-benzoquinone (O-TCBQ) (Fang et al., 2000; Zimbron and Reardon, 2009; Lan et al., 2008), as well as their hydroxylation products such as $\operatorname{TrCBQ}-\mathrm{OH}$ and DDBQ (Zhu et al., 2007a, 2007b, 2009, 2012). Indeed, we found that five of these six transient quinoid intermediates were formed in the PCP/Fe(II)-EDTA/ $\mathrm{H}_{2} \mathrm{O}_{2}$ system by High Performance Liquid Chromatography (HPLC) analysis (Mao et al., 2015) (Fig. 3A and B). Interestingly, when reacted with $\mathrm{H}_{2} \mathrm{O}_{2}$, these tetrachloroquinoid compounds also produced weak CL, which was greatly enhanced by addition of Fe(II)-EDTA (Mao et al., 2015). Further studies showed that these quinoid intermediates could be further decomposed to several ring-opening products such as DCMA and $\mathrm{CO}_{2}$ (and/or CO) (about 83.6\% PCP can be mineralized to inorganic carbon after $2 \mathrm{hr}$ ) (Fig. 3C and D).

\subsection{CL could also be produced by PCP with other .OH-generating systems}

Further studies showed that CL could be produced not only with the classic Fe(II)-mediated Fenton systems, but also with other .OH-involved AOPs such as redox-active metal-mediated Fenton-like systems including $\mathrm{Co}(\mathrm{II})-\mathrm{EDTA} / \mathrm{H}_{2} \mathrm{O}_{2}, \mathrm{~V}(\mathrm{IV})$-EDTA/ $\mathrm{H}_{2} \mathrm{O}_{2}$, and $\mathrm{Cr}(\mathrm{III})-\mathrm{EDTA} / \mathrm{H}_{2} \mathrm{O}_{2}$ (Fig. 4A), as well as the well-known ozonation systems, including $\mathrm{O}_{3}$ and $\mathrm{O}_{3} / \mathrm{H}_{2} \mathrm{O}_{2}$ (Fig. 4B). .OH was also produced by all these systems (Fig. $4 \mathrm{C}$ and $\mathrm{D}$ ).

\subsection{Possible molecular mechanism for CL production during .OH-dependent PCP degradation}

On the basis of the above results and our previous findings (Zhu et al., 2007b, 2012), we proposed the following molecular mechanism for .OH-dependent CL emission from pentahalogenated phenols (PXP) with $\mathrm{Fe}(\mathrm{II})-\mathrm{EDTA} / \mathrm{H}_{2} \mathrm{O}_{2}$ (Mao et al., 2015) (Scheme 2): .OH first attacks PXP, via electron transfer and/or electrophilic addition, forming pentahalophenoxyl radical and tetrahalosemiquinone radical (Fang et al., 2000; Weavers et al., 2000; Fukushima and Tatsumi, 2001), which would further convert to the initial tetrahaloquinoid intermediates. The nucleophilic reaction may take place between these tetrahaloquinoid intermediates and $\mathrm{H}_{2} \mathrm{O}_{2}$, generating unusually highly-energetic quinone-1,2-dioxetanes in the presence of .OH. These quinone-1,2-dioxetanes further decompose to form the electronically excited carbonyl species [L]*. The CL at a broad
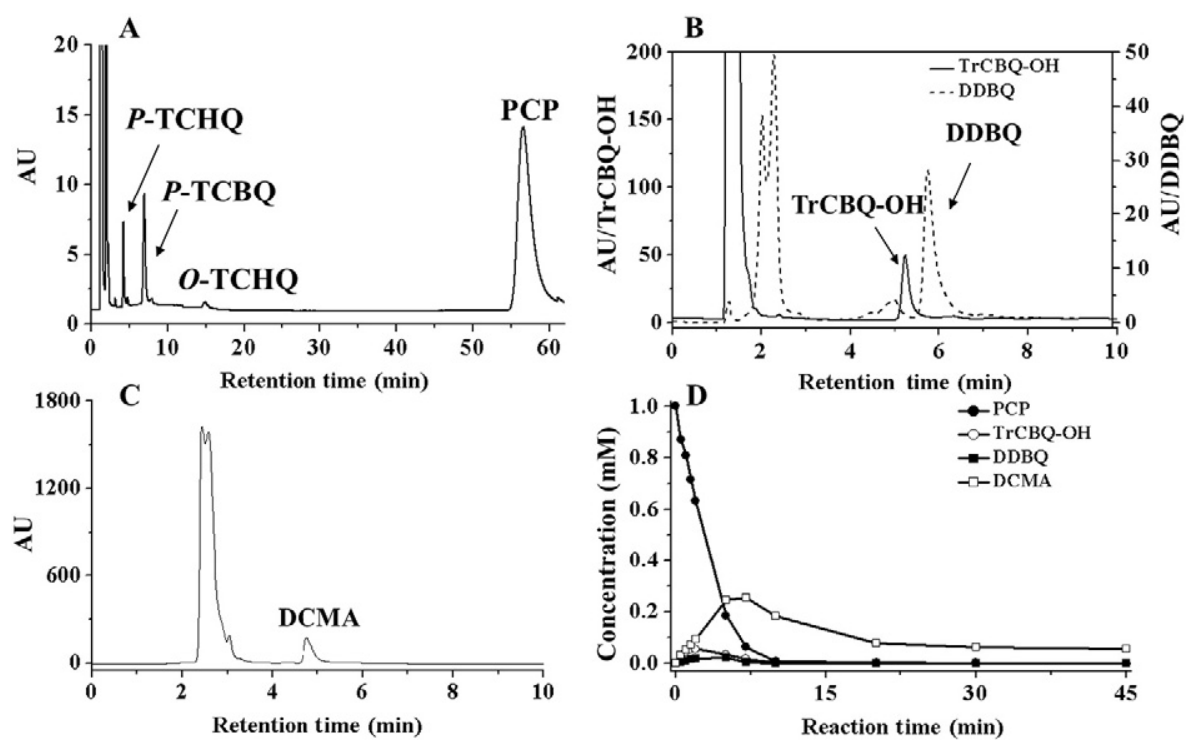

Fig. 3 - Identification and quantification of chlorinated quinoid intermediates and ring-opening products from the reaction of PCP with Fe(II)-EDTA/ $\mathrm{H}_{2} \mathrm{O}_{2}$ (modified on ref. (Mao et al., 2015)). (A) PCP, P-TCHQ, P-TCBQ and O-TCHQ; (B) TrCBQ-OH and DDBQ; (C) DCMA; (D) The degradation of PCP and formation of TrCBQ-OH, DDBQ, and DCMA. For the separation and identification of PCP, P-TCHQ, P-TCBQ and O-TCHQ: PCP, $1 \mathrm{mM}$; Fe(II)-EDTA, $2 \mathrm{mM} ; \mathrm{H}_{2} \mathrm{O}_{2}, 1 \mathrm{mM}$. For the identification and quantification of TrCBQ-OH, DDBQ and DCMA: PCP, 1 mM; Fe(II)-EDTA, 3 mM; $\mathrm{H}_{2} \mathrm{O}_{2}$, 300 mM P-TCHQ: tetrachloro-p-hydroquinone; O-TCHQ: tetrachloro-o-hydroquinone; DDBQ: 2,5-dichloro-3,6-dihydroxyl-p-benzoquinone; DCMA: dichloromaleic acid. 

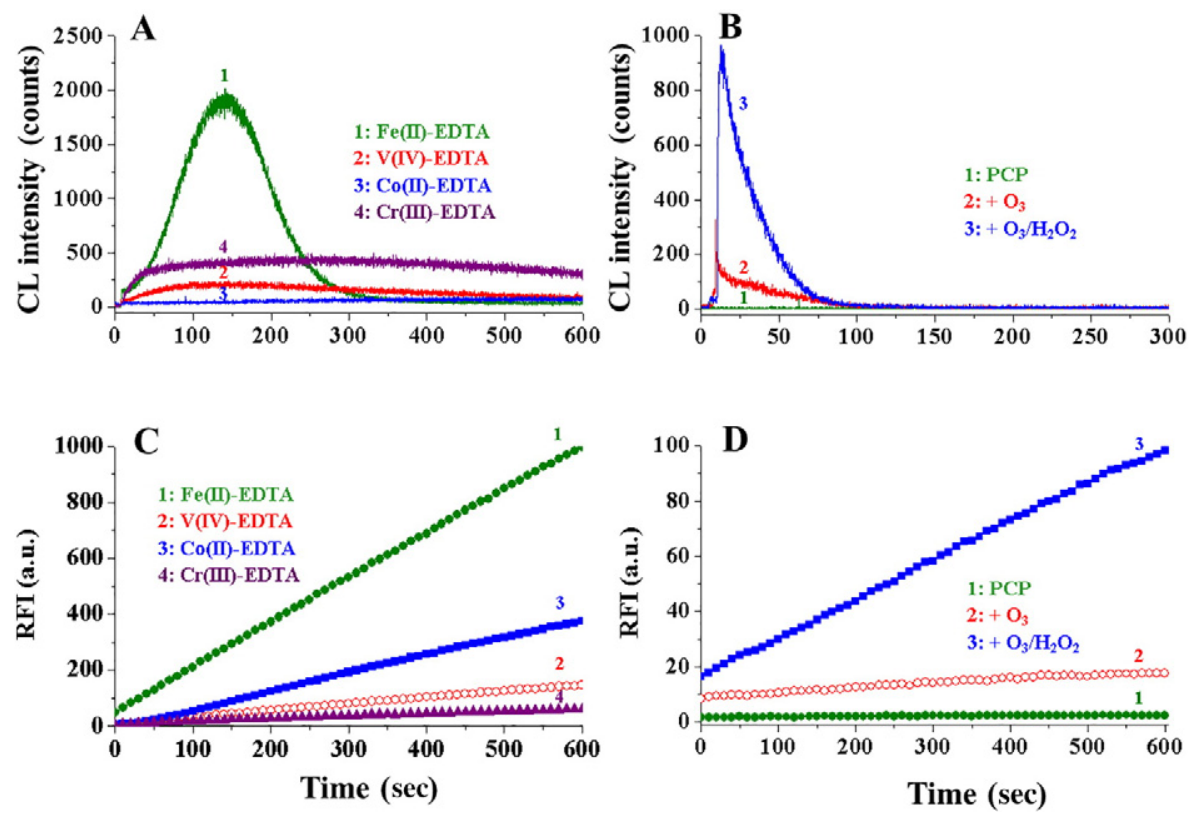

Fig. 4 - Similar .OH-dependent CL emission could be also observed during the reaction of PCP with other .OH-generating systems (modified on ref. (Mao et al., 2015)). (A) and (B): CL could also be produced when PCP was treated with other .OH-generating system including Fenton-like and ozonation systems; (C) and (D): The fluorescent kinetic study on .OH generation by Fenton-like and ozonation systems. For CL generation, in Fenton-like systems (A): PCP, $0.02 \mathrm{mmol} / \mathrm{L}$; Fe(II)EDTA, V(IV)-EDTA, Co(II)-EDTA, Cr(III)-EDTA, $1 \mathrm{mmol} / \mathrm{L} ; \mathrm{H}_{2} \mathrm{O}_{2}, 100 \mathrm{mmol} / \mathrm{L}$; in ozonation systems (B): phosphate buffer was purged with $\mathrm{O}_{3}$ for $60 \mathrm{sec}$ before reaction, and then quickly introduce PCP (or PCP with $\mathrm{H}_{2} \mathrm{O}_{2}$ ) into the reaction mixtures. PCP, $0.1 \mathrm{mmol} / \mathrm{L} ; \mathrm{H}_{2} \mathrm{O}_{2}, 100 \mathrm{mmol} / \mathrm{L}$. For .OH detection by fluorescent method, in Fenton-like systems (C): PCP, $2 \mu \mathrm{mol} / \mathrm{L} ; \mathrm{Fenton}-$ like agents, $0.1 \mathrm{mmol} / \mathrm{L} ; \mathrm{H}_{2} \mathrm{O}_{2}, 10 \mathrm{mmol} / \mathrm{L} ; \mathrm{TPA}, 4 \mathrm{mmol} / \mathrm{L}$; in ozonation systems: PCP, $0.1 \mathrm{mmol} / \mathrm{L} ; \mathrm{H}_{2} \mathrm{O}_{2}, 100 \mathrm{mmol} / \mathrm{L} ; \mathrm{TPA}, 4 \mathrm{mmol} /$ L. Co(II): Cobalt(II); V(IV): Vanadium(IV); Cr(III): Chromium(III); TPA: terephthalic acid.

band of $510-580 \mathrm{~nm}$ (PCP for example) is emitted when the electronically excited state of $[\mathrm{L}]^{*}$ returns to its ground state $[\mathrm{L}]$, and the subsequent decomposition of [L] leads to the formation of the final ring-opening products DCMA and $\mathrm{CO}_{2}$ (and/or CO).

\section{A structure-activity relationship study on the intrinsic CL production from the degradation of all 19 CPs by Fenton system: the critical role of quinoid and semiquinone radical intermediates}

\subsection{All 19 CPs could produce CL during the .OH-generating AOPs}

From the above studies, we already knew that CL can be produced by PCP with $\mathrm{Fe}(\mathrm{II})-\mathrm{EDTA} / \mathrm{H}_{2} \mathrm{O}_{2}$. Then, it would be interesting to know whether CL could also be produced by other CPs with the classic Fenton system; and if so, what is the potential structure-activity relationship? As anticipated, we found that analogous .OH-dependent CL emission could be observed when PCP was substituted by other 18 CP congeners (Fig. 5). Interestingly, we found that the CL intensity of CPs in Fenton system was not only correlated to the chlorination level, but also to the spatial distribution of the chloro-substitution. The following SAR between the chemical structures of CPs and CL generation were observed (Mao et al., 2015): 1) the CL intensity increases with increasing number of chloro-substitution;
2) among the CP isomers, CPs with position-2, -3 or -5 chlorosubstitution (which are considered stimulative sites) exhibit stronger CL, whereas those with position-4 or -6 chlorosubstitution (inhibitory sites) produce relatively weaker CL. Thus, 2,5-dichlorophenol (DCP), 2,3,5-TCP, and 2,3,5,6tetrachlorophenol (TeCP) produced the highest CL emission among their corresponding DCP, TCP and TeCP isomers. However, there are clear exceptions for the two general trends. For example, the CL produced by most highly chlorinated PCP is weaker than that of 2,3,5,6-TeCP with lower chlorination.

Similar to the case of PCP, other CPs can also be oxidized by . $\mathrm{OH}$ during AOPs to produce several chlorinated quinoid intermediates such as chloro-p-hydroquinones (P-CHQs), chloro-p-benzoquinones (P-CBQs), chloro-o-hydroquinones (O-CHQs) and chloro-o-benzoquinones (O-CBQs) (Fang et al., 2000; Mao et al., 2015; Czaplicka, 2006). Three of these four chlorinated quinoid compounds, including P-CHQs, P-CBQs and $\mathrm{O}$-CHQs, were indeed identified as the major quinoid degradation intermediates for the six TCP isomers, three TeCP isomers and PCP (Table 1) (Gao et al., 2016, 2017). For example, 2,3,4,6-TeCP could produce trichloro- $p$-benzoquinone (P-TrCBQ), trichloro- $p$ hydroquinone $(\mathrm{P}-\mathrm{TrCHQ}), 3,4,6$-trichloro-o-hydroquinone (3,4,6-O$\operatorname{TrCHQ})$, and 3,4,5-trichloro-o-hydroquinone (3,4,5-O-TrCHQ). However, O-CBQs were not detected, possibly due to their extreme instability. Based on the formation of the same chlorinated quinoid compound P-CHQs/P-CBQs, the three kinds of CPs can be divided into five different groups (Table 1). 

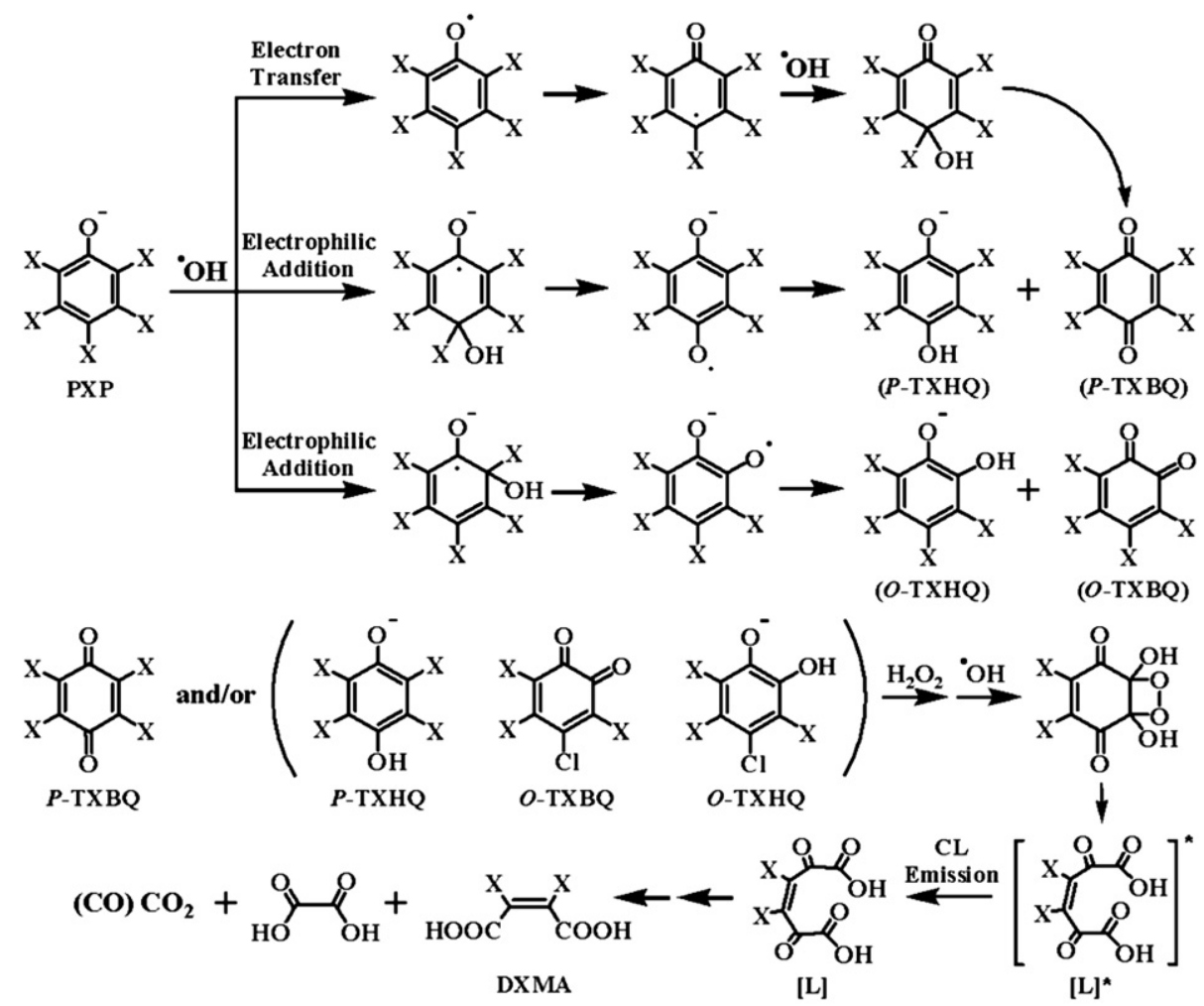

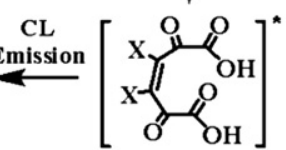

[L]^

$\mathrm{X}: \mathbf{C l}, \mathbf{F}, \mathbf{B r}$

Scheme 2 - Proposed molecular mechanism for .OH-dependent CL production by PXP/Fe(II)-EDTA/ $\mathrm{H}_{2} \mathrm{O}_{2}$ (modified on ref. (Mao et al., 2015)).

\subsection{A good correlation was observed between CL emission and the formation of chlorinated quinoid intermediates}

As mentioned above, CL could be produced by the interaction of several kinds of $\mathrm{P}-\mathrm{CBQ}$ s and $\mathrm{O}-\mathrm{CHQ}$ s with $\mathrm{H}_{2} \mathrm{O}_{2}$ (Zhu et al., 2012). A more detailed study was then conducted under different experimental conditions, and we found (Fig. 6A and B) that (Gao et al., 2017): 1) the CL emission of P-CBQs increased with increasing number of chlorine atoms on the quinone ring, i.e., $p$-benzoquinone $(\mathrm{P}-\mathrm{BQ})<\mathrm{P}-\mathrm{CBQ}<$ dichloro- $p$-benzoquinone (P-DCBQ) isomers $<\mathrm{P}-\operatorname{TrCBQ}<\mathrm{P}$-TCBQ; 2) among the three $P$-DCBQ isomers, the order of $C L$ emission is 2,3-P$\mathrm{DCBQ}<2,6-\mathrm{P}-\mathrm{DCBQ}<2,5-\mathrm{P}-\mathrm{DCBQ} ; 3)$ the CL emission was especially strong for O-TCHQ and 3,4,6-O-TrCHQ but much weaker for other O-CHQs. Therefore, we speculated that the CL intensity of CPs might be mainly dependent on the yields and types of the P-CBQs (since P-CHQs can also be further oxidized to form P-CBQs) and that of the O-CHQs (3,4,6-O-TrCHQ/O-TCHQ). As discussed below, this was found to be indeed the case.

The maximum yields of each quinoid intermediate produced by CPs were summarized in Table 1 . We can see that there is indeed a good correlation between CL production and the total yields of their corresponding quinoid intermediate P-CHQs/P-CBQs and O-TCHQ/3,4,6-O-TrCHQ (the two O-CHQs with the stronger CL emission), especially for those CPs which could produce the same $P$-CHQ/P-CBQ intermediates (Fig. 6C and $\mathrm{D}$, taking PCP and three TeCP isomers for example) (Gao et al., 2016, 2017).
From the above studies, two general principles were observed on CL production from $\mathrm{P}-\mathrm{CBQ}$ s and $\mathrm{O}-\mathrm{CHQ}$ in Fenton system: (1) Among P-CBQs and O-CHQs, P-TCBQ O-TCHQ and 3,4,6-O-TrCHQ produced relative stronger CL emission; (2) For the same $\mathrm{P}-\mathrm{CBQ}$ s and $\mathrm{O}-\mathrm{CHQ}$, the higher yields of $\mathrm{P}-\mathrm{CBQ}$ s and $\mathrm{O}-\mathrm{CHQ}$ s were produced, the stronger the $\mathrm{CL}$ emission. Interestingly, the trend of CL emission from the CPs can be well explained by the above two basic principles (Gao et al., 2016).

For example, the CL intensity of the three TeCPs and PCP increases in the following order: $2,3,4,6-\mathrm{TeCP}<2,3,4,5-\mathrm{TeCP}<$ $\mathrm{PCP}<2,3,5,6-\mathrm{TeCP}$. This is because the yield of P-TCBQ/P-TCHQ produced by $2,3,5,6-\mathrm{TeCP}$ is higher than that by PCP; in addition, the CL emission of 3,4,6-O-TrCHQ produced by 2,3,5,6-TeCP was stronger than that of O-TCHQ produced by PCP. Although 3,4,6-O-TrCHQ could also be produced by 2,3,4,6-TeCP, the yields of $\mathrm{P}$-TrCBQ/P-TrCHQ and O-TCHQ produced by 2,3,4,5-TeCP were all higher than those of $\mathrm{P}-\mathrm{TrCBQ} / \mathrm{P}-\mathrm{TrCHQ}$ and 3,4,6-O-TrCHQ produced by 2,3,4,6-TeCP, respectively. Therefore, when taking into account of both the yields and the types of $\mathrm{P}-\mathrm{CHQ} / \mathrm{P}-\mathrm{CBQ}$ and $\mathrm{O}-\mathrm{CHQ}$ s produced by TeCPs and PCP with Fenton system, the unusual CL emission by 2,3,5,6-TeCP can be readily explained.

\subsection{Possible molecular basis for the correlation between CL and chlorinated quinoid intermediates}

When .OH attacks on CPs, the types and yields of the chlorinated quinoid intermediates ( $\mathrm{P}-\mathrm{CHQ} / \mathrm{P}-\mathrm{CBQ}$ and $\mathrm{O}-\mathrm{CHQ}$ ) were determined by the basic physiochemical properties of $\mathrm{CPs}$, 


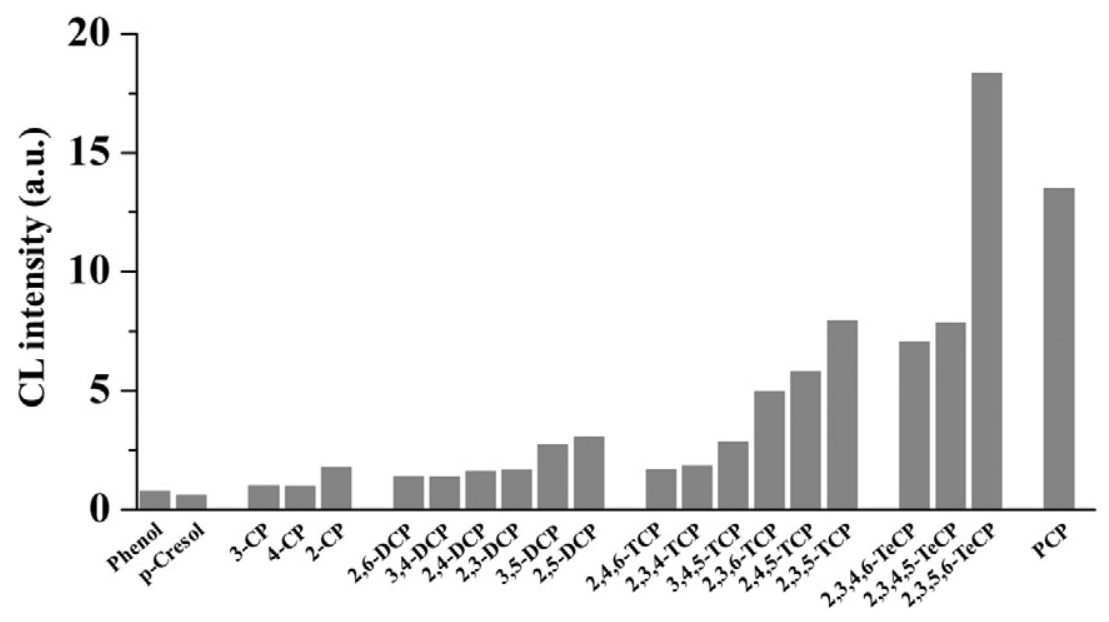

Fig. 5 - Not only PCP, but also all 19 chlorinated phenols could produce .OH-dependent CL emission in the presence of $\mathrm{Fe}$ (II)-EDTA/ $\mathrm{H}_{2} \mathrm{O}_{2}$ (modified on ref. (Mao et al., 2015)). Phenol and chlorophenols, $0.01 \mathrm{mmol} / \mathrm{L} ; \mathrm{Fe}(\mathrm{II})-\mathrm{EDTA}, 1 \mathrm{mmol} / \mathrm{L} ; \mathrm{H} \mathrm{O}_{2}$, $100 \mathrm{mmol} / \mathrm{L}$.

which include the electron-withdrawing properties of $\mathrm{Cl}$ atoms and the directing effects of $-\mathrm{OH}$ and $-\mathrm{Cl}$ groups as listed below (Gao et al., 2017): (1) As the number of electron-withdrawing - Cl groups increases, the $\pi$-electron density in aromatic ring decreases, and as a result, it makes the phenolic ring less favorable for electrophilic attack by .OH; however, it makes the quinone ring more favorable for nucleophilic attack by $\mathrm{H}_{2} \mathrm{O}_{2}$ (Zhu et al., 2007b); (2) Although both $-\mathrm{OH}$ and $-\mathrm{Cl}$ are orthoand para-directing groups for further substitution or addition by . $\mathrm{OH}$, the directing power by $-\mathrm{OH}$ is much stronger than $-\mathrm{Cl}$ (Carey, 2000), thus, the types of P-CBQs/P-CHQs and O-CHQs formation are mainly dependent on $-\mathrm{OH}$ group; (3) When $-\mathrm{Cl}$ groups were at the meta positions of the phenolic ring, the directing effects of $-\mathrm{OH}$ and meta- $\mathrm{Cl}$ will reinforce each other, and the reactions with $\mathrm{OH}$ should be highly regioselective for ortho- and para-positions (more P-CBQs/P-CHQs should be formed); (4) Meanwhile, for chlorophenol isomers, if more $-\mathrm{Cl}$ were at the meta positions of the phenolic ring, more highly chlorinated hydroquinones and catechols would be produced by .OH attack, since the dechlorination was less likely to occur; (5) .OH attacks more readily on ortho- and para-positions not occupied by $-\mathrm{Cl}$ groups. It is well known that the more negative charge density of $\mathrm{C}$ atom on the aromatic ring, the more favorable the electrophilic .OH would attack it. Density functional theory (DFT) calculations revealed that the charge density of the free positions are indeed more negative than positions

Table 1 - Maximum yields of the major chlorinated quinoid intermediates detected during the degradation of corresponding CPs by Fenton system (modified on ref. (Gao et al., 2016, 2017)).

\begin{tabular}{|c|c|c|c|c|c|c|c|c|}
\hline \multirow{3}{*}{$\begin{array}{c}\text { CPs } \\
\text { PCP }\end{array}$} & \multicolumn{8}{|c|}{ Chloroquinoid intermediates (mmol/L) } \\
\hline & \multicolumn{2}{|c|}{$P$-CBQs } & \multicolumn{2}{|c|}{$P$-CHQs } & \multicolumn{4}{|c|}{$O$-CHQs } \\
\hline & $P$-TCBQ & 0.024 & $P$-TCHQ & 0.109 & $O$-TCHQ & 0.068 & & \\
\hline 2,3,5,6-ТеCP & $P$-TCBQ & 0.095 & $P$-TCHQ & 0.151 & 3,4,6-O-TrCHQ & 0.110 & & \\
\hline 2,3,4,5-TeCP & $P$-TrCBQ & 0.010 & $P$-TrCHQ & 0.088 & $O$-TCHQ & 0.058 & $3,4,5-O-\operatorname{TrCHQ}$ & 0.036 \\
\hline 2,3,4,6-ТеCP & $P$-TrCBQ & 0.008 & $P$-TrCHQ & 0.083 & 3,4,6-O-TrCHQ & 0.051 & $3,4,5-O-\operatorname{TrCHQ}$ & 0.033 \\
\hline 2,3,5-TCP & $P$-TrCBQ & 0.0144 & $P$-TrCHQ & 0.1362 & 3,4,6-O-TrCHQ & 0.1191 & 3,5-O-DCHQ & 0.0337 \\
\hline 2,3,6-TCP & $P$-TrCBQ & 0.0165 & $P$-TrCHQ & 0.1265 & 3,6-O-DCHQ & 0.0350 & 3,4-O-DCHQ & 0.0334 \\
\hline 2,4,5-ТCP & 2,5-P-DCBQ & 0.0054 & 2,5-P-DCHQ & 0.1081 & 3,4,6-O-TrCHQ & 0.1996 & 4,5-O-DCHQ & 0.0335 \\
\hline 3,4,5-ТCP & 2,6-P-DCBQ & 0.0067 & 2,6-P-DCHQ & 0.0653 & 3,4,5-O-TrCHQ & 0.3024 & & \\
\hline 2,4,6-ТCP & 2,6-P-DCBQ & 0.0021 & 2,6-P-DCHQ & 0.0422 & 3,5-O-DCHQ & 0.0608 & & \\
\hline 2,3,4-TCP & 2,3-P-DCBQ & 0.0084 & 2,3-P-DCHQ & 0.0690 & 3,4,5-O-TrCHQ & 0.1112 & 3,4-O-DCHQ & 0.0441 \\
\hline \multicolumn{9}{|c|}{$\begin{array}{l}\text { CPs: chlorinated phenols; P-CBQs: chloro-p-benzoquinones; P-CHQs: chloro-p-hydroquinones; O-CHQs: } \\
\text { chloro-o-hydroquinones; PCP: pentachlorophenol; TeCP: tetrachlorophenol; TCP: trichlorophenol; P-TCBQ: } \\
\text { tetrachloro-p-benzoquinone; P-TrCBQ: trichloro-p-benzoquinone; P-DCBQ: dichloro-p-benzoquinone; } \\
\text { P-TrCHQ: trichloro-p-hydroquinone; 3,4,5-O-TrCHQ: 3,4,5-trichloro-o-hydroquinone; 3,4,6-O-TrCHQ: } \\
\text { 3,4,6-trichloro-o-hydroquinone; P-DCHQ: dichloro-p-hydroquinone; O-DCHQ: dichloro-o-hydroquinone. } \\
\text { Chlorophenols: } 1 \mathrm{mmol} / \mathrm{L} ; \mathrm{H}_{2} \mathrm{O}_{2}: 1 \mathrm{mmol} / \mathrm{L} ; \mathrm{Fe}^{2+} \text {-EDTA: } 3 \mathrm{mmol} / \mathrm{L} \text {. }\end{array}$} \\
\hline
\end{tabular}



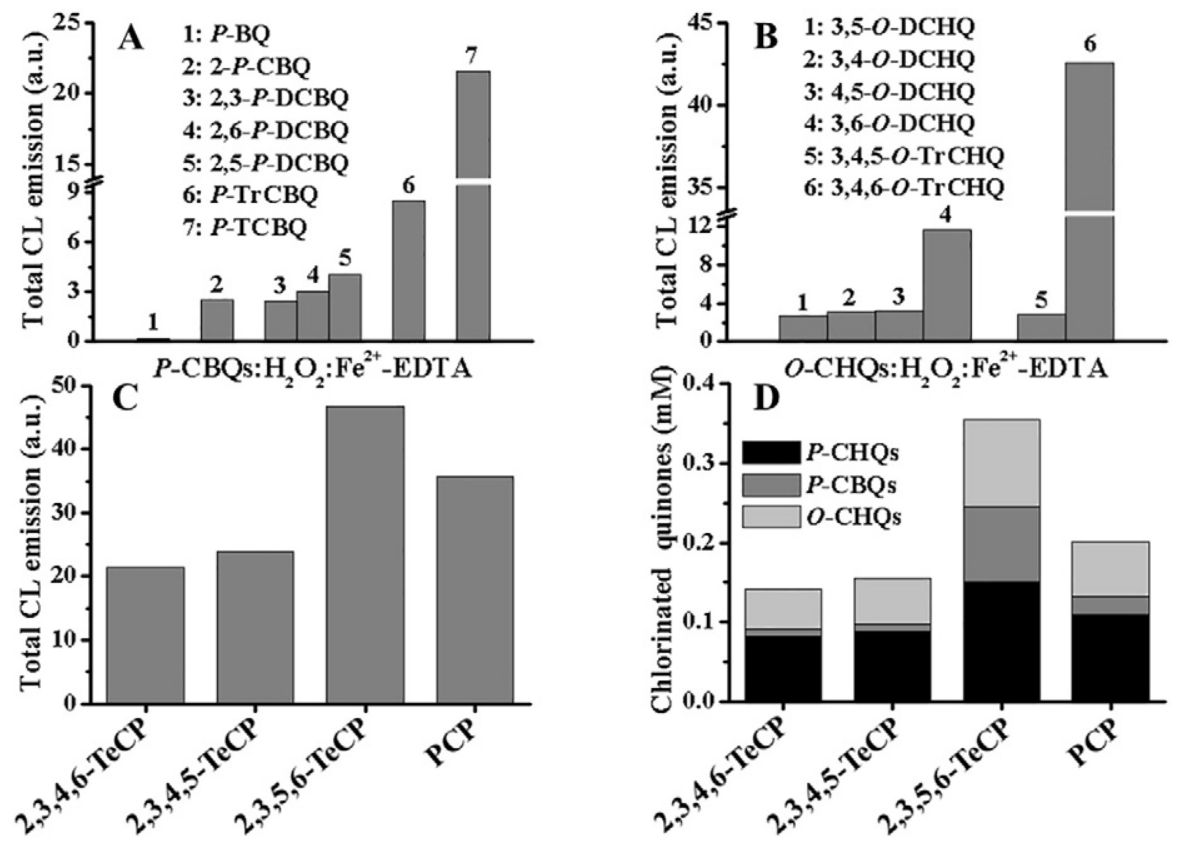

Fig. 6 - A good correlation was observed between CL emission and the formation of the chlorinated quinoid intermediates (modified on ref. (Gao et al., 2016, 2017)). (A) and (B) The trend of CL emission from P-CBQs and O-CHQs. P-CBQs and O-CHQs, $0.03 \mathrm{mmol} / \mathrm{L} ; \mathrm{H}_{2} \mathrm{O}_{2}, 100 \mathrm{mmol} / \mathrm{L}$; Fe(II)-EDTA, $1 \mathrm{mmol} / \mathrm{L}$; (C) CL emission from TeCPs and PCP. TeCPs and PCP, 0.03 mmol/L; $\mathrm{H}_{2} \mathrm{O}_{2}, 100 \mathrm{mmol} / \mathrm{L} ; \mathrm{Fe}(\mathrm{II})-\mathrm{EDTA}, 1 \mathrm{mmol} / \mathrm{L}$; (D) The total yields of P-CHQs/P-CBQs and O-CHQs. TeCPs and PCP, $1 \mathrm{mmol} / \mathrm{L} ; \mathrm{H}_{2} \mathrm{O}_{2}$, $1 \mathrm{mmol} / \mathrm{L}$; Fe(II)-EDTA, $3 \mathrm{mmol} / \mathrm{L} . P-C B Q s:$ chloro-p-benzoquinones; O-CHQs: chloro-o-hydroquinones; TeCPs: tetrachlorophenols; P-CHQs: chloro-p-hydroquinones.

occupied by - $\mathrm{Cl}$ (Akai et al., 2001) (Table 2); (6) Cl at position-2 is very difficult to be attacked by .OH, due to both steric hindrance effect (Tang and Huang, 1995) and the intramolecular hydrogen bonding (Kishino and Kobayashi, 1994) between - $\mathrm{OH}$ and $-\mathrm{Cl}$ groups; (7) Even if the two ortho-positions were both substituted by $\mathrm{Cl}$ atoms, the steric hindrance effects of the $\mathrm{Cl}$ atom at position- 2 were always stronger than that at position- 6 based on IUPAC nomenclature rules. Thus, on the aromatic ring, the sites readily attacked by .OH are position -4 and -6 , not position- 2 . The combination of the above seven factors should play decisive roles in SAR for CL produced by CPs/Fenton system.

To further illustrate the role of these factors in SAR for CL, three typical TCP isomers (2,3,5-, 2,4,5-, and 2,4,6-TCP) were taken as example for detailed analysis. As shown in Scheme 3, the $-\mathrm{OH}$ group should determine the sites attacked by. $\mathrm{OH}$ on the phenolic ring (noted as the solid arrows), while the meta-Cl groups should determine the reactivity of TCPs attacked by .OH (noted as the dashed arrows); In other words, the more the dashed arrows at the ortho- and para-positions, the more readily the hydroxylation occur, resulting in higher yield of P-CHQs/P-CBQs, and then the stronger CL production by the corresponding TCPs. Therefore, based on the number of the dashed arrows, the order of CL emission for the three TCPs should be 2,3,5-TCP > 2,4,5-TCP > 2,4,6-TCP, which is in good agreement with the experimental results (Fig. 5).

3.4. A good correlation was also observed between CL emission and the formation of the chlorinated $p$-semiquinone radicals

It has been well-accepted that the cyclic (auto)oxidation and reduction reactions of $\mathrm{P}-\mathrm{CHQ}$ and $\mathrm{P}$-CBQs can produce the intermediary of chlorinated $p$-semiquinones ( $P$-CSQs) (Zhu and Shan, 2009; Bolton et al., 2000). However, to our knowledge, no evidence of P-CSQs. formation has been reported during the degradation of CPs by Fenton system, although P-CSQs. can be detected in other .OH-generating systems (Zimbron and Reardon, 2009; Hong and Zeng, 2002; Han et al., 1998). The reason is possibly due to the rapid formation and decay of P-CSQs. during the high yields of . $\mathrm{OH}$ in Fenton system. To solve this problem, stopped-flow technique, which is suitable for the kinetic study of fast reactions, was employed. As anticipated, we successfully observed the typical ESR spectra of P-CSQs. generation from $\mathrm{CPs} /$ Fenton system under the real CL-producing experimental conditions by using this method (Table 3) (Gao et al., 2016, 2017). Interestingly, a good correlation was also observed between P-CSQs. formation and. $\mathrm{OH}$ production by Fenton system: the more .OH produced, the faster the formation of P-CSQs (Gao et al., 2016, 2017). Interestingly, based on the formation of the same P-CSQ. intermediates, CPs can also be classified into several sub-groups, which agree well with the above proposed several sub-groups based on the formation of the same $p$-quinoid intermediates (P-CHQs/P-CBQs) (Table 3). For the example of TCPs, both trichloro- $p$-semiquinone ( $P$-TrCSQ) and P-TrCHQ/ P-TrCBQ can be produced by 2,3,5-TCP and 2,3,6-TCP; and both dichloro-p-semiquinone (2,6-P-DCSQ) and dichloro- $p$-hydroquinone (2,6-P-DCHQ)/2,6-P-DCBQ can be produced by 2,4,6-TCP and 3,4,5-TCP.

These results demonstrate that the SAR for CL is closely correlated not only to the formation of the quinoid transient product, but also to that of the chlorinated semiquinone radical intermediates. 
Table 2-Charge distribution in chlorophenols obtained from

DFT calculations (modified on ref. (Gao et al., 2016, 2017)).

\begin{tabular}{|c|c|c|c|c|c|}
\hline CPs & Position & Partial charge & CPs & Position & Partial charge \\
\hline & 2 & 0.200 & & 2 & 0.139 \\
\hline & 4 & 0.112 & & 4 & 0.078 \\
\hline PCP & 6 & 0.224 & $2,3,4,5-\mathrm{TeCP}$ & 6 & -0.213 \\
\hline & 2 & 0.168 & & 2 & 0.232 \\
\hline & 4 & -0.311 & & 4 & 0.246 \\
\hline $2,3,5,6-\mathrm{TeCP}$ & 6 & 0.193 & $\begin{array}{c}\mathrm{Cl} \\
2,3,4,6-\mathrm{TeCP}\end{array}$ & 6 & 0.379 \\
\hline & 2 & 0.140 & & 2 & -0.263 \\
\hline & 4 & -0.337 & & 4 & 0.054 \\
\hline $2,3,5-\mathrm{TCP}$ & 6 & -0.260 & $\begin{array}{c}\mathrm{Cl} \\
\mathbf{c l}, 4-\mathrm{TCP} \\
\end{array}$ & 6 & -0.282 \\
\hline & 2 & 0.217 & & 2 & 0.375 \\
\hline & 4 & -0.194 & & 4 & 0.385 \\
\hline 2,3,6-TCP & 6 & 0.317 & $\begin{array}{c}\mathrm{Cl} \\
2,4,6-\mathrm{TCP}\end{array}$ & 6 & 0.393 \\
\hline он & 2 & 0.321 & & 2 & 0.182 \\
\hline $\mathrm{Cl}_{4}^{1 / 4}$ & 4 & 0.221 & & 4 & 0.217 \\
\hline $\begin{array}{c}\mathrm{c} \\
2,4,5-\mathrm{TCP}\end{array}$ & 6 & -0.186 & $\begin{array}{c}\mathrm{Cl} \\
2,3,4-\mathrm{TCP}\end{array}$ & 6 & -0.106 \\
\hline
\end{tabular}

\subsection{Relatively good correlations between CL and the toxicity/degradation rate of CPs were also observed}

It is well known that SAR approach has been widely used to predict toxicity/degradation rate and to study the mechanism of toxicity and degradation (Tang and Huang, 1995; Smith et al., 1994; Padmanabhan et al., 2006; Kishino and Kobayashi, 1996; Chen and Lin, 2006; Antonaraki et al., 2002; Parra et al., 2003; Oturan et al., 2009). Therefore, the SAR for CL production by $\mathrm{CPs} /$ Fenton system might provide useful information for predicting the toxicity/degradation rate of CPs.

It has been found previously that the toxicity of CPs to various living organisms also significantly depends on the number and position of the chlorine atoms in the aromatic ring (Padmanabhan et al., 2006; Kishino and Kobayashi, 1996; Chen and Lin, 2006). We also observed similar results on SAR between the acute toxicity of CPs to Photobacterium phosphoreum and their chemical structure (Gao et al., 2017) (Table 4): 1) the toxicity of CPs increased with increasing number of chlorine atoms; 2) for CP isomers, the toxicity decreased in the order of non- < mono- < di-ortho-chlorophenols (i.e., 3-/4-/ 5- > 2-/6-chloro-substituted phenols).

In addition, there were many studies on the relationship between the number and position of chlorine substituents and the degradation rate of CPs by .OH (Tang and Huang, 1995;
Antonaraki et al., 2002; Oturan et al., 2009): the degradation rate constants decreased with the increase of the number of chlorine substitution, especially for the highly CPs, whereas for the CP isomers, the reduced degradation rate in the order of 3-/5- > 2-/4-/6-chloro-substituted phenols. This was also found to be the case in our research (Mao et al., 2015).

Compared our study with the previous studies (Tang and Huang, 1995; Smith et al., 1994; Padmanabhan et al., 2006) on SARs between the toxicity/degradation rate and the chemical structure of CPs, we found that there are some good correlations between CL and the toxicity/degradation rate of CPs (although there are some exceptions): 1) In general, CPs exhibit the stronger CL, higher toxicity and slower degradation rate with increasing number of chlorine substitution; 2) For each isomeric groups, CPs with position- 3 or/and -5 substitutions, such as $3-\mathrm{CP}$, 3,5-DCP, 3,4,5-TCP and 2,3,4,5-TeCP, exhibit relatively stronger $\mathrm{CL}$, higher toxicity and faster degradation rate compared to other corresponding isomers; whereas those with position- 6 substituents, such as 2,6-DCP, 2,4,6-TCP and 2,3,4,6-TeCP, possess the weakest $\mathrm{CL}$, the lowest toxicity and the slowest degradation rate. These correlations may be due to similar or even the same dominating physiochemical factors such as the directing effect, intramolecular hydrogen bonding and steric hindrance effect of - $\mathrm{OH}$ - $\mathrm{Cl}$ groups, as well as the electron-withdrawing properties of $\mathrm{Cl}$ atoms.
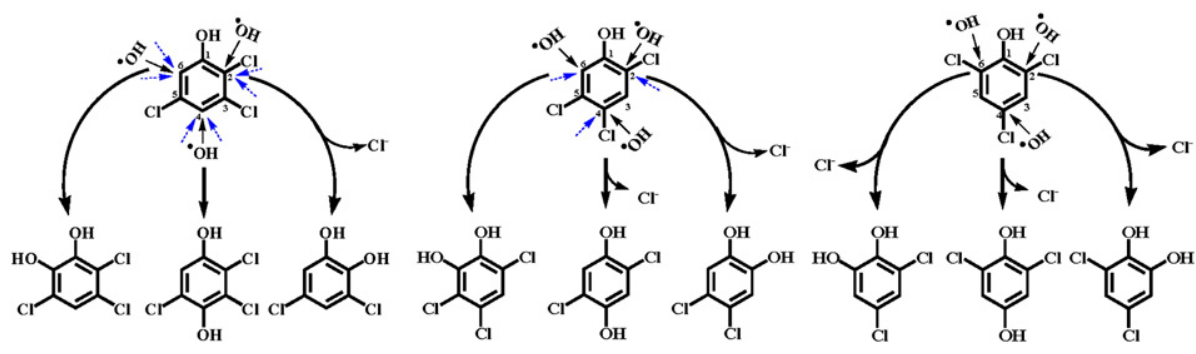

Scheme 3 - The formation of chlorinated hydroquinoid intermediates as determined by the directing effect of - OH group during the degradation of trichlorophenols (TCPs) by Fenton system (modified on ref. (Gao et al., 2017)). TCPs: trichlorophenols. 
Table 3 -ESR spectra and $g$ values of P-CSQs.- produced during the degradation of CPs by Fenton system (modified on ref. ( )).

\begin{tabular}{|c|c|c|c|c|}
\hline CPs & $\begin{array}{c}\text { ESR } \\
\text { spectra }\end{array}$ & $P$-CSQs ${ }^{\bullet-}$ & $a^{\mathrm{H}}$ & $g$ Value \\
\hline $\begin{array}{c}\text { РСР } \\
\text { 2,3,5,6-ТeCP }\end{array}$ & $\sqrt{10 \mathrm{G}}$ & $P$-TCSQ ${ }^{*-}$ & - & 2.0054 \\
\hline $\begin{array}{c}2,3,4,5-\mathrm{TeCP} \\
2,3,4,6-\mathrm{TeCP} \\
2,3,5-\mathrm{TCP} \\
2,3,6-\mathrm{TCP}\end{array}$ & & $P$-TrCSQ ${ }^{--}$ & 2.17 & 2.0051 \\
\hline 2,4,5-ТCP & $-1 / 2$ & 2,5-P-DCSQ ${ }^{\circ-}$ & 1.96 & 2.0049 \\
\hline $\begin{array}{l}3,4,5-\mathrm{TCP} \\
2,4,6-\mathrm{TCP}\end{array}$ & -1/hm & 2,6-P-DCSQ ${ }^{\circ-}$ & 2.40 & 2.0049 \\
\hline 2,3,4-ТCP & $-N_{h}$ & 2,3-P-DCSQ ${ }^{--}$ & 2.35 & 2.0050 \\
\hline
\end{tabular}

TeCP: tetrachlorophenol; TCP: trichlorophenol; ESR: electron spin resonance; P-CSQs: chlorinated $p$-semiquinones; P-TCSQ: tetrachloro- $p$-semiquinone; $\quad P$-TrCSQ: trichloro- $p$-semiquinone; P-DCSQ: dichloro-p-semiquinone.

4. Intrinsic CL could also be produced from all XAr tested during their advanced degradation by .OH-generating systems

Finally, we extended our study from CPs to other halogenated phenols and then to other XAr. We found that CL could also be produced by all other halogenated phenols, such as PBP, PFP, the flame retardant 3,3',5,5'-tetrabromobisphenol A (TBBPA), and the broad-spectrum antibacterial personal care agent triclosan (Fig. 7). In fact, CL could be observed with all XAr tested (Mao et al., 2015). These include: the widely used chlorophenoxyacetic acid herbicides such as 2,4-dichlorophenoxyacetic acid (2,4-D) and 2,4,5-trichlorophenoxyacetic acid (2,4,5-T), which are the major components of Agent Orange; iodinated aromatic pharmaceuticals, such as triiodothyronine (T3) and thyroxine (T4); new chlorination disinfection haloquinoid byproducts in drinking water, such as 2,6-dichloro- and trichloro-p-benzoquinone (P-TrCBQ) (Zhao et al., 2010); halogenated benzene biocides, such as pentachlorobenzene (PCB); polyhalogenated diphenyl ether flame retardants, such as BDE 79; polyhalogenated biphenyl dielectric and coolant fluids, such as trichlorobiphenyl (and their corresponding diphenols and the quinones). These results indicate that .OH-dependent CL production during advanced oxidation is a general phenomenon for all XAr tested, but each compound exhibits a distinct CL emission profile.

\section{Potential applications of our findings}

The fact that all tested XAr that could produce. $\mathrm{OH}$-dependent CL during their advanced oxidation may have interesting chemical, biological, environmental, pharmaceutical, and toxicological implications. Many widely used XAr, which are considered POPs and probable human carcinogens, can be degraded, detoxified, and mineralized in various .OH-mediated AOPs (Gupta et al., 2002; Sorokin et al., 1995; Zhang and Huang, 2003; Zhong et al., 2012; Peller et al., 2003). These XAr not only cause oxidative damage to DNA and other macromolecules, but also form protein and DNA adducts both in vitro and in vivo (Song et al., 2009; Chignell et al., 2008; Teuten et al., 2005; Kelly et al., 2007), and therefore, are potentially carcinogenic toward mammalian organisms. Consequently, it is important to detect and measure these ubiquitous polyhalogenated pollutants or pharmaceutics both in the environment and in biological systems.

It is well known that CL-based analytical methods are inherently sensitive due to the relative ease with which low light emission can be quantified by photon-counting techniques. Therefore, we might use the CL-producing property to detect and quantify trace amounts of XAr. As anticipated, by employing this highly sensitive CL method, we can quantitatively measure trace amount of several typical model XAr such as PCP, triclosan, TBBPA, P-TrCBQ PCB, 2,4-D, 2,4,5-T, T3 and T4 (Mao et al., 2015).

This CL-based method can also be applied to detect and measure possible XAr present in real environmental samples such as the discharge from a paper-mill (Mao et al., 2015). We found that CL could be produced from the paper-mill discharge in the presence of $\mathrm{Fe}(\mathrm{II})-\mathrm{EDTA} / \mathrm{H}_{2} \mathrm{O}_{2}$, and further investigation indicated that the discharge indeed contained several XAr, including 4-chlorophenol, 2,4-DCP and other chlorinated aromatics by gas chromatography/mass spectrometer (GC/MS) analysis coupled with enrichment through solid phase extraction (SPE). These results suggest that the CL-based method we developed could be used to evaluate potential XAr contamination in real environmental samples.

Table 4 - The IC $_{50}$ values of all 19 chlorophenols in Photobacterium phosphoreum test (modified on ref. (

\begin{tabular}{|c|c|c|c|c|c|c|c|}
\hline CPs & $\mathrm{IC}_{50}(\mu \mathrm{mol} / \mathrm{L})$ & $\log K_{\mathrm{OW}}$ & $\mathrm{pKa}$ & CPs & $\mathrm{IC}_{50}(\mu \mathrm{mol} / \mathrm{L})$ & $\log K_{\mathrm{OW}}$ & $\mathrm{pKa}$ \\
\hline Phenol & 2936.58 & 1.48 & 9.89 & 2,3,6-ТCP & 249.92 & 3.88 & 7.12 \\
\hline 2-CP & 639.25 & 2.17 & 8.48 & 2,4,6-ТCP & 233.53 & 3.69 & 7.41 \\
\hline $3-\mathrm{CP}$ & 504.59 & 2.5 & 8.84 & 2,3,4-ТCP & 12.25 & 4.07 & 7.64 \\
\hline 4-CP & 222.1 & 2.35 & 9.17 & 2,4,5-ТCP & 8.11 & 3.72 & 7.42 \\
\hline 2,6-DCP & 224.87 & 2.86 & 6.78 & 2,3,5-TCP & 7.35 & 4.21 & 7.35 \\
\hline 2,3-DCP & 133.99 & 3.19 & 6.43 & $3,4,5-\mathrm{TCP}$ & 2.94 & 4.39 & 8.24 \\
\hline 2,5-DCP & 117.61 & 3.2 & 6.33 & 2,3,4,6-ТеCР & 105.86 & 4.24 & 5.47 \\
\hline 3,4-DCP & 53.68 & 3.37 & 7.37 & 2,3,5,6-ТеCP & 72.54 & 4.9 & 5.03 \\
\hline 2,4-DCP & 51.48 & 3.08 & 7.66 & $2,3,4,5-\mathrm{TeCP}$ & 1.86 & 4.95 & 7.03 \\
\hline 3,5-DCP & 29.17 & 3.52 & 6.91 & РCP & 44.22 & 5.01 & 5.06 \\
\hline
\end{tabular}

DCP: dichlorophenol; TeCP: tetrachlorophenol; IC 50 : 50\% inhibitory concentration. 
<smiles>Oc1c(Cl)c(Cl)c(Cl)c(Cl)c1Cl</smiles><smiles>[14CH3][14CH2]c1cc(Br)c(O)c(Br)c1</smiles><smiles>CC(C)(c1cc(Br)c(O)c(Br)c1)c1cc(Br)c(Br)c(Br)c1</smiles><smiles>Oc1cc(Cl)ccc1Oc1ccc(Cl)cc1Cl</smiles><smiles>O=C(O)C(=O)Oc1cc(Cl)cc(Cl)c1Cl</smiles><smiles>Clc1cc(Cl)c(Cl)c(Cl)c1Cl</smiles>
PCB<smiles>O=C(O)COc1cc(Cl)c(Cl)cc1Cl</smiles>
2,4,5-T<smiles></smiles>
Trichlorobiphenyl<smiles>Brc1cc(Br)cc(Oc2ccc(Br)c(Br)c2)c1</smiles>
BDE 79

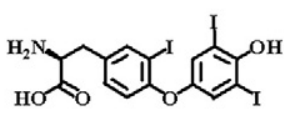

Triiodothyronine (T3)
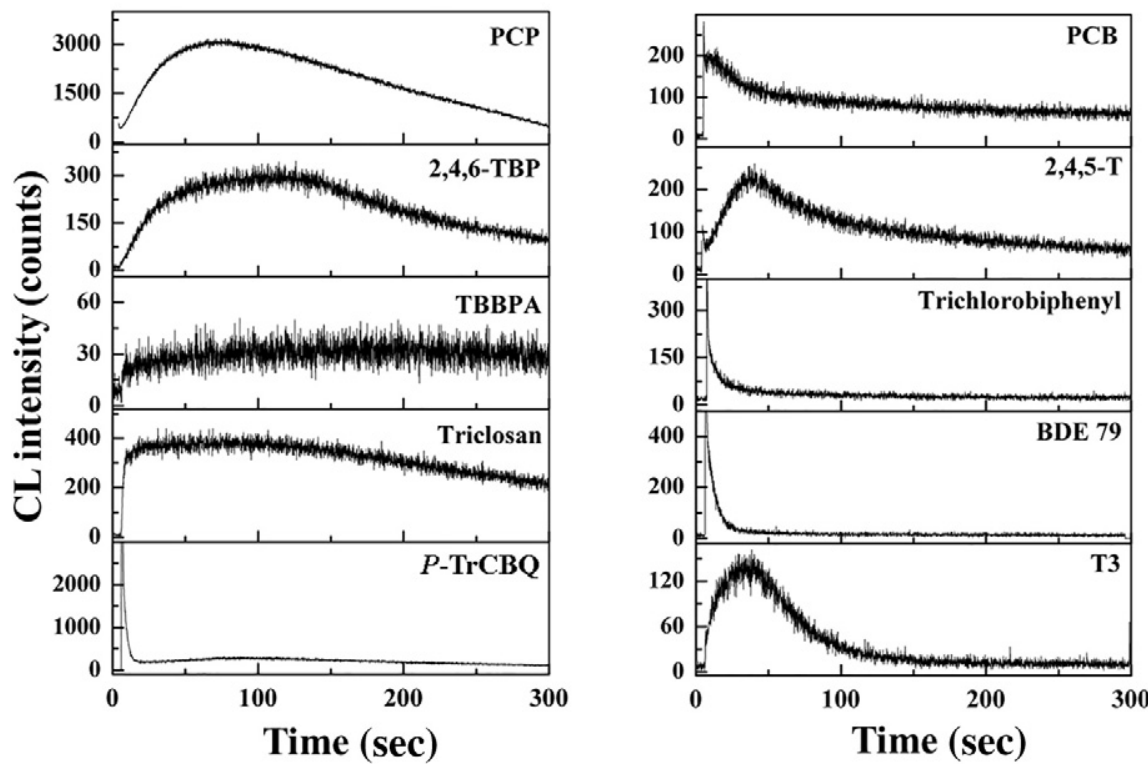

Fig. 7 - .OH-dependent CL could also be produced by several typical classes of XAr (modified on ref. (Mao et al., 2015)). For the CL emission of BDE 79 and trichlorobiphenyl: Fe(II)-EDTA, $2 \mathrm{mmol} / \mathrm{L} ; \mathrm{H}_{2} \mathrm{O}_{2}, 1 \mathrm{mmol} / \mathrm{L}$. For other XAr: Fe(II)-EDTA, $1 \mathrm{mmol} / \mathrm{L} ; \mathrm{H}_{2} \mathrm{O}_{2}$, $100 \mathrm{mmol} / \mathrm{L}$. PCP, 2,4,6-TBP, TBBPA, triclosan, P-TrCBQ, PCB, 2,4,5-T, $30 \mu \mathrm{mol} / \mathrm{L}$; trichlorobiphenyl, $200 \mu \mathrm{mol} / \mathrm{L}$; BDE 79, $500 \mu \mathrm{mol} / \mathrm{L}$; T3, $3 \mu \mathrm{mol} / \mathrm{L}$.TBBPA: tetrabromobisphenol A; PCB: pentachlorobenzene; 2,4,6-TBP: 2,4,6-tribromophenol.

Haloaromatics are degraded and detoxified during AOPs to low-toxic small molecules or even mineralized to inorganic $\mathrm{CO}_{2}$ or CO. Therefore, during the practical remediation process, the kinetics of XAr degradation is often monitored to evaluate the efficiency of the remediation techniques. The traditional method, such as HPLC (Gupta et al., 2002; Sorokin et al., 1995; Zhang and Huang, 2003; Weavers et al., 2000; Sun and Pignatello, 1993), used to monitor the kinetics of XAr degradation during AOPs is not only relatively time-consuming, but also consumes large amounts of solvents. Thus, a rapid, sensitive, simple, and effective method to monitor the degradation kinetics of XAr is urgently needed.

We found that the new CL-based method could also be used for this purpose. In the PCP/Fe(II)-EDTA/ $\mathrm{H}_{2} \mathrm{O}_{2}$ system, we found that the $\mathrm{CL}$ emission kinetics correlate well with the degradation kinetic curves of PCP as measured by HPLC. The time course of CL emission was accompanied concurrently with the degradation of PCP, and when the degradation level of PCP and the chlorine ions release reached the maximum, no further CL emission could be observed (Fig. 8).

It is well known that SAR approaches have been wildly used to predict the toxicity of several toxic compounds (Tang and Huang, 1995; Smith et al., 1994; Padmanabhan et al., 2006; Kishino and Kobayashi, 1996; Chen and Lin, 2006; Antonaraki et al., 2002; Parra et al., 2003; Oturan et al., 2009). In our work, as discussed above, the SAR established for CL production by CPs/ Fenton system might provide useful information for predicting the toxicity of CPs, which would be more convenient than traditional theoretical calculations coupled with modeling.

Another potential application for the CL-based method is to detect. $\mathrm{OH}$ production when coupled with typical .OHscavenging agents since the CL produced by .OH-generating systems with XAr was found to be directly and specifically dependent on $\mathrm{OH}$ production, but not on other ROS, such as superoxide anion radical and singlet oxygen.

\section{Conclusions}

In our work, we first report that intrinsic CL could be produced by halogenated quinones (such as P-TCBQ) with $\mathrm{H}_{2} \mathrm{O}_{2}$ and the CL production is directly and specifically dependent on. $\mathrm{OH}$ formation. Further investigation revealed that PCP, the precursors of $\mathrm{P}$-TCBQ could also produce intrinsic . OH-dependent CL during the advanced oxidation mediated by .OH-generating system. Interestingly, all $19 \mathrm{CPs}$ and other tested XAr could produce analogous .OH-dependent CL emission.

Meanwhile, the fact that CL could be produced by CPs and other XAr during .OH-involved AOPs may imply that this unique CL-producing property can be used to detect and 

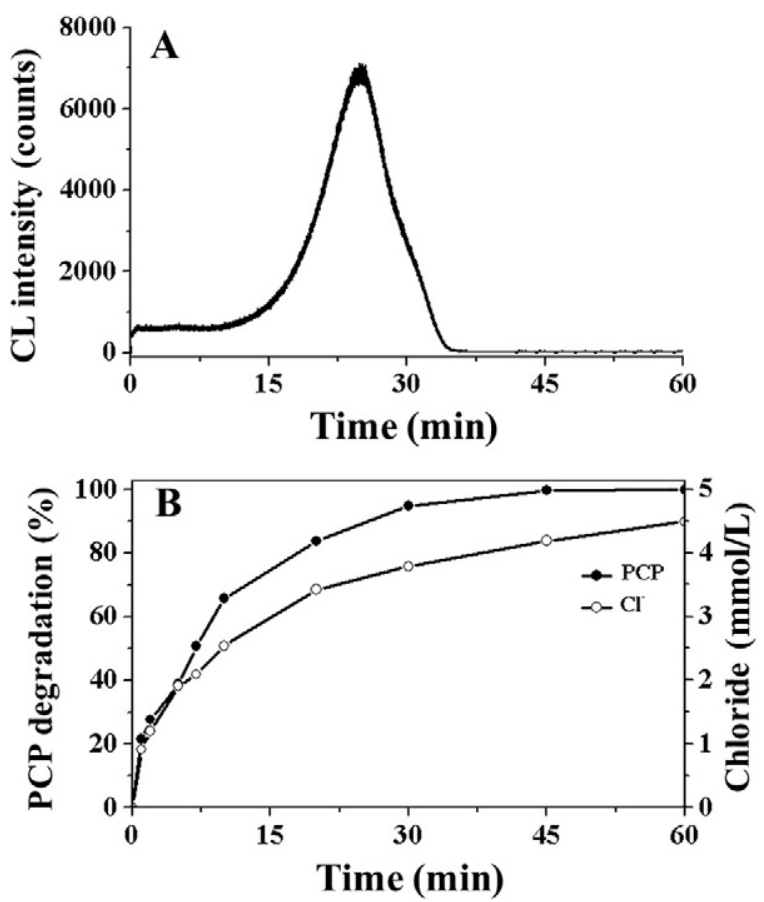

Fig. 8 - Good correlations were observed between CL emissions (A) and degradation kinetics (B) during advanced oxidation of PCP (modified on ref. (Mao et al., 2015)). PCP, $1 \mathrm{mmol} / \mathrm{L} ; \mathrm{Fe}(\mathrm{II})-\mathrm{EDTA}, 1 \mathrm{mmol} / \mathrm{L} ; \mathrm{H}_{2} \mathrm{O}_{2}, 100 \mathrm{mmol} / \mathrm{L}$.

measure highly toxic XAr, an important class of compounds of major environmental and biomedical concern. Indeed, we took advantage of this finding and employed this highly sensitive CL method to not only measure quantitatively trace amounts of $\mathrm{XAr}$, but also to measure XAr in real sample. Furthermore, we reported the first detailed SAR study between CL and the critical role of quinoid intermediates (and especially semiquinone radicals). On the basis of the above results, this novel CL-dependent method can be used not only to detect and measure trace amounts of XAr in both pure and real samples, but also to provide useful information for predicting the toxicity/degradation rate of XAr (especially for CPs). Therefore, these new findings may have broad chemical, biological and environmental implications for future studies on XAr.

\section{Acknowledgment}

The work in this paper was supported by the Strategic Priority Research Program of CAS (No. XDB01020300); NSF China Grants (Nos. 21577149, 21477139, 21237005 and 21321004); and NIH Grants (Nos. ES11497, RR01008 and ES00210).

\section{R E F E R E N C E S}

Adam, W., Kazakov, D.V., Kazakov, V.P., 2005. Singlet-oxygen chemiluminescence in peroxide reactions. Chem. Rev. 105, 3371-3387.

Akai, N., Kudoh, S., Takayanagi, M., Nakata, M., 2001. Photoreaction mechanisms of 2-chlorophenol and its multiple chloro-substituted derivatives studied by low-temperature matrix-isolation infrared spectroscopy and density-functionaltheory calculations. J. Photochem. Photobiol. A 146, 49-57.
Almeida de Oliveira, M., Bartoloni, F.H., Augusto, F.A., Ciscato, L.F., Bastos, E.L., Baader, W.J., 2012. Revision of singlet quantum yields in the catalyzed decomposition of cyclic peroxides. J. Organomet. Chem. 77, 10537-10544.

Antonaraki, S., Androulaki, E., Dimotikali, D., Hiskia, A., Papaconstantinou, E., 2002. Photolytic degradation of all chlorophenols with polyoxometallates and $\mathrm{H}_{2} \mathrm{O}_{2}$. J. Photochem. Photobiol. A 148, 191-197.

Bolton, J.L., Trush, M.A., Penning, T.M., Dryhurst, G., Monks, T.J., 2000. Role of quinones in toxicology. Chem. Res. Toxicol. 13, 135-160.

Bos, R., Tonkin, S.A., Hanson, G.R., Hindson, C.M., Lim, K.F., Barnett, N.W., 2009. In search of a chemiluminescence 1,4-dioxy biradical. J. Am. Chem. Soc. 131, 2770-2771.

Cannizzaro, V., Bowie, A.R., Sax, A., Achterberg, E.P., 2000. Determination of cobalt and iron in estuarine and coastal waters using flow injection with chemiluminescence detection. Analyst 125, 51-57.

Carey, F.A., 2000. Organic Chemistry. 4th ed. McGraw-Hill Higher Education, USA, pp. 463-472.

Chen, C.Y., Lin, J.H., 2006. Toxicity of chlorophenols to Pseudokirchneriella subcapitata under air-tight test environment. Chemosphere 62, 503-509.

Chignell, C.F., Han, S.K., Mouithys-Mickalad, A., Sik, R.H., Stadler, K., Kadiiska, M.B., 2008. EPR studies of in vivo radical production by $3,3^{\prime}, 5,5^{\prime}$-tetrabromobisphenol A (TBBPA) in the Sprague-Dawley rat. Toxicol. Appl. Pharmacol. 230, 17-22.

Chu, W., 1999. Photodechlorination mechanism of DDT in a UV/surfactant system. Environ. Sci. Technol. 33, 421-425.

Czaplicka, M., 2006. Photo-degradation of chlorophenols in the aqueous solution. J. Hazard. Mater. 134, 45-59.

Dann, A.B., Hontela, A., 2010. Triclosan: environmental exposure, toxicity and mechanisms of action. J. Appl. Toxicol. 31, 285-311.

De Wit, C., 2002. A. An overview of brominated flame retardants in the environmental. Chemosphere 46, 583-624.

Fang, X.W., Schuchmann, H.P., von Sonntag, C., 2000. The reaction of the $\mathrm{OH}$ radical with pentafluoro-, pentachloro-, pentabromo- and 2,4,6-triiodophenol in water: electron transfer vs. addition to the ring. J. Chem. Soc. Perkin Trans. 2, 1391-1398. 
Fukushima, M., Tatsumi, K., 2001. Degradation pathways of pentachlorophenol by photo-Fenton systems in the presence of iron(III), humic acid and hydrogen peroxide. Environ. Sci. Technol. 35, 1771-1778.

Gao, H.Y., Mao, L., Shao, B., Huang, C.H., Zhu, B.Z., 2016. Why does 2,3,5,6-tetrachlorophenol generate the strongest intrinsic chemiluminescence among all nineteen chlorophenolic persistent organic pollutants during environmentally-friendly advanced oxidation process? Sci Rep 6:33159. http://dx.doi.org/ 10.1038/srep33159.

Gao, H.Y., Mao, L., Li, F., Xie, L.N., Huang, C.H., Shao, J., Shao, B., Kalyanaraman, B., Zhu, B.Z., 2017. Mechanism of intrinsic chemiluminescence production from the degradation of persistent chlorinated phenols by the Fenton system: a structure-activity relationship study and the critical role of quinoid and semiquinone radical intermediates. Environ. Sci. Technol. 51, 2934-2943.

Goldstein, S., Meyerstein, D., Czapski, G., 1993. The Fenton reagents. Free Radic. Biol. Med. 15, 435-445.

Grayeski, M.L., 1987. Chemiluminescence analysis. Anal. Chem. 59, 1243A-1256A.

Gupta, S.S., Stadler, M., Noser, C.A., Ghosh, A., Steinhoff, B., Lenoir, D., Horwitz, C.P., Schramm, K.W., Collins, T.J., 2002. Rapid total destruction of chlorophenols by activated hydrogen peroxide. Science 296, 326-328.

Halliwell, B., Gutteridge, J.M.C., 2007. Free Radicals in Biology and Medicine. Oxford University Press, Oxford.

Han, S.K., Ichikawa, K., Utsumi, H., 1998. Generation of p-semiquinone radicals from chlorophenols in water during ozonation. Water Res. 32, 1978-1981.

Hong, P.K.A., Zeng, Y., 2002. Degradation of pentachlorophenol by ozonation and biodegradability of intermediates. Water Res. 36, 4243-4254.

Huang, C.H., Shan, G.Q., Mao, L., Kalyanaraman, B., Zhu, B.Z., 2013. The first purification and unequivocal characterization of the radical form of the carbon-centered quinone ketoxy radical adduct. Chem. Commun. 49, 6436-6439.

Huang, C.H., Ren, F.R., Shan, G.Q., Qin, H., Mao, L., Zhu, B.Z., 2015. Molecular mechanism of metal-independent decomposition of organic hydroperoxides by the halogenated quinoid carcinogens and the potential biological implications. Chem. Res. Toxicol. 28, 831-837.

IARC Working Group, 2016. International Agency for Research on Cancer Volume 117: pentachlorophenol and some related compounds. Lyon; 4-11 October 2016. IARC Monogr. Eval. Carcinog. Risk Chem. Hum.

Jia, S., Zhu, B.Z., Guo, L.H., 2010. Detection and mechanistic investigation of halogenated benzoquinone induced DNA damage by photoelectrochemical DNA sensor. Anal. Bioanal. Chem. 397, 2395-2400.

Kanakubo, A., Isobe, M., 2005. Isolation of brominated quinones showing chemiluminescence activity from luminous acorn worm, Ptychodera flava. Bioorg. Med. Chem. 13, 2741-2747.

Kelly, B.C., Ikonomou, M.G., Blair, J.D., Morin, A.E., Gobas, F.A.P.C., 2007. Food web-specific biomagnification of persistent organic pollutants. Science 317, 236-239.

Kishino, T., Kobayashi, K., 1994. Relation between the chemical structures of chlorophenols and their dissociation constants and partition coefficients in several solvent-water systems. Water Res. 28, 1547-1552.

Kishino, T., Kobayashi, K., 1996. Acute toxicity and structure-activity relationships of chlorophenols in fish. Water Res. 30, 387-392.

Lan, Q., Li, F., Liu, C., Li, X.Z., 2008. Heterogeneous photodegradation of pentachlorophenol with maghemite and oxalate under UV illumination. Environ. Sci. Technol. 42, 7918-7923.

Lente, G., Espenson, J.H., 2003. Photoaccelerated oxidation of chlorinated phenols. Chem. Commun. 1163-1163.
Liao, C., Chung, T., Che, W., Kuo, S., 2007. Treatment of pentachlorophenol-contaminated soil using nano-scale zerovalent iron with hydrogen peroxide. J. Mol. Catal. A Chem. 265, 189-194.

Lin, J.M., Yamada, M., 2000. Chemiluminescent reaction of fluorescent organic compounds with KHSO5 using cobalt (II) as catalyst and its first application to molecular imprinting. Anal. Chem. 72, 1148-1155.

Lin, Z., Chen, H., Zhou, Y., Ogawa, N., Lin, J.M., 2012. Self-catalytic degradation of ortho-chlorophenol with Fenton's reagent studied by chemiluminescence. J. Environ. Sci. 24, 550-557.

Liou, R., Che, S., Hung, M., Hsu, C., 2004. Catalytic oxidation of pentachlorophenol in contaminated soil suspensions by $\mathrm{Fe}^{+3}$-resin $/ \mathrm{H}_{2} \mathrm{O}_{2}$. Chemosphere 55, 1271-1280.

Mao, L., Liu, Y.X., Huang, C.H., Gao, H.Y., Kalyanaraman, B., Zhu, B.Z., 2015. Intrinsic chemiluminescence generation during advanced oxidation of persistent halogenated aromatic carcinogens. Environ. Sci. Technol. 49, 7940-7947.

Matsumoto, M., 2004. Advanced chemistry of dioxetane-based chemiluminescent substrates originating from bioluminescence. J. Photochem. Photobiol. C 5, 27-53.

McCapra, F., 2000. Chemical generation of excited states: the basis of chemiluminescence and bioluminescence. Methods Enzymol. 305, 3-47.

Meunier, B., 2002. Catalytic degradation of chlorinated phenols. Science 296, 270-271.

Montzka, S.A., Krol, M., Dlugokencky, E., Hall, B., Jöckel, P., Lelieveld, J., 2011. Small interannual variability of global atmospheric hydroxyl. Science 331, 67-69.

Oturan, N., Panizza, M., Oturan, M.A., 2009. Cold incineration of chlorophenols in aqueous solution by advanced electrochemical process electro-Fenton. Effect of number and position of chlorine atoms on the degradation kinetics. J. Phys. Chem. A 113, 10988-10993.

Padmanabhan, J., Parthasarathi, R., Subramanian, V., Chattaraj, P.K., 2006. Group philicity and electrophilicity as possible descriptors for modeling ecotoxicity applied to chlorophenols. Chem. Res. Toxicol. 19, 356-364.

Parra, S., Olivero, J., Pacheco, L., Pulgarin, C., 2003. Structural properties and photoreactivity relationships of substituted phenols in $\mathrm{TiO}_{2}$ suspensions. Appl. Catal. B 43, 293-301.

Peller, J., Wiest, O., Kamat, P.V., 2003. Mechanism of hydroxyl radical-induced breakdown of the herbicide 2,4dichlorophenoxyacetic acid (2,4-D). Chem. Eur. J. 9, 5379-5387.

Pera-Titus, M., García-Molina, V., Baños, M.A., Giménez, J., Esplugas, S., 2004. Degradation of chlorophenols by means of advanced oxidation processes: a general review. Appl. Catal. B Environ. 47, 219-256.

Qin, H., Huang, C.H., Shan, G.Q., Mao, L., Kalyanaraman, B., Zhu, B.Z., 2013. Molecular mechanism of metal-independent decomposition of lipid hydroperoxide 13-HPODE by halogenated quinoid carcinogens. Free Radic. Biol. Med. 63, 459-466.

Ramamoorthy, S., 1997. Chlorinated Organic Compounds in the Environment: Regulatory and Monitoring Assessment. CRC Press, Boca Raton, FL.

Rohrer, F., Berresheim, H., 2006. Strong correlation between levels of tropospheric hydroxyl radicals and solar ultraviolet radiation. Nature 442, 184-187.

Schuster, G.B., 1979. Chemiluminescence of organic peroxides. Conversion of ground-state reactants to excited-state products by the chemically initiated electron-exchange luminescence mechanism. Acc. Chem. Res. 12, 366-373.

Shao, J., Huang, C.H., Kalyanaraman, B., Zhu, B.Z., 2013. Potent methyl oxidation of 5-methyl-2'-deoxycytidine by halogenated quinoid carcinogens and hydrogen peroxide via a metal-independent mechanism. Free Radic. Biol. Med. 60, 177-182. 
Smith, S., Furay, V.J., Layiwola, P.J., Menezes-Filho, J.A., 1994. Evaluation of the toxicity and quantitative structure-activity relationships (QSAR) of chlorophenols to the copepodid stage of a marine copepod (Tisbe battagliai) and two species of benthic flatfish, the flounder (Platichthys flesus) and sole (Solea solea). Chemosphere 28, 825-836.

Song, Y., Wagner, B.A., Witmer, J.R., Lehmler, H.J., Buettner, G.R., 2009. Nonenzymatic displacement of chlorine and formation of free radicals upon the reaction of glutathione with PCB quinones. Proc. Natl. Acad. Sci. U. S. A. 106, 9725-9730.

Sorokin, A., Seris, J.L., Meunier, B., 1995. Efficient oxidative dechlorination and aromatic ring-cleavage of chlorinated phenols catalyzed by iron sulfophthalocyanine. Science 268, 1163-1166.

Sun, Y., Pignatello, J.J., 1993. Photochemical reactions involved in the total mineralization of 2,4-D by Fe ${ }^{3+} / \mathrm{H}_{2} \mathrm{O}_{2} / \mathrm{UV}$. Environ. Sci. Technol. 27, 304-310.

Tang, W.Z., Huang, C.P., 1995. The effect of chlorine position of chlorinated phenols on their dechlorination kinetics by Fenton's reagent. Waste Manag. 15, 615-622.

Teuten, E.L., Xu, L., Reddy, C.M., 2005. Two abundant bioaccumulated halogenated compounds are natural products. Science 307, 917-920.

Voinov, M.A., Pagan, J.O.S., Morrison, E., Smirnova, T.I., Smirnov, A.I., 2011. Surface-mediated production of hydroxyl radicals as a mechanism of iron oxide nanoparticle biotoxicity. J. Am. Chem. Soc. 133, 35-41.

Von Sonntag, C., 2008. Advanced oxidation process: mechanistic aspects. Water Sci. Technol. 58, 1015-1021.

Wagner, J.R., Cadet, J., 2010. Oxidation reactions of cytosine DNA components by hydroxyl radical and one-electron oxidants in aerated aqueous solutions. Acc. Chem. Res. 43, 564-571.

Wang, J.N., Xu, L.J., 2012. Advanced oxidation processes for wastewater treatment: formation of hydroxyl radical and application. Crit. Rev. Environ. Sci. Technol. 42, 251-325.

Wang, D., Zhao, L., Guo, L.H., Zhang, H., 2014. Online detection of reactive oxygen species in ultraviolet (UV)-irradiated nano- $\mathrm{TiO}_{2}$ suspensions by continuous flow chemiluminescence. Anal. Chem. 86, 10535-10539.

Wardman, P., Candeias, L.P., 1996. Fenton chemistry: an introduction. Radiat. Res. 145, 523-531.

Weavers, L.K., Malmstadt, N., Hoffmann, M.R., 2000. Kinetics and mechanism of pentachlorophenol degradation by sonication, ozonation, and sonolytic ozonation. Environ. Sci. Technol. 34, 1280-1285.

Widder, E.A., 2010. Bioluminescence in the ocean: origins of biological, chemical, and ecological diversity. Science 328, 704-708.

Xu, G., Chance, M.R., 2007. Hydroxyl radical-mediated modification of proteins as probes for structural proteomics. Chem. Rev. 107, 3514-3543.

Yin, R., Zhang, D., Song, Y., Zhu, B.Z., Wang, H., 2013. Potent DNA damage by polyhalogenated quinoid carcinogens and $\mathrm{H}_{2} \mathrm{O}_{2}$ via a metal-independent and intercalation-enhanced oxidation mechanism. Sci Rep 3:1269. http://dx.doi.org/10.1038/srep01269.
Zhang, H., Huang, C.H., 2003. Oxidative transformation of triclosan and chlorophene by manganese oxides. Environ. Sci. Technol. 37, 2421-2430.

Zhao, Y.L., Qin, F., Boyd, J.M., Anichina, J., Li, X.F., 2010 Characterization and determination of chloro- and bromo-benzoquinones as new chlorination disinfection byproducts in drinking water. Anal. Chem. 82, 4599-4605.

Zhao, B., Yang, Y., Wang, X., Chong, Z., Yin, R., Song, S.H., et al., 2014. Redox-active quinones induce genome-wide DNA methylation changes by an iron-mediated and Tet-dependent mechanism. Nucleic Acids Res. 42, 1593-1605.

Zhong, Y.H., Liang, X., Zhong, Y., Zhu, J., Zhu, S., Yuan, P., He, H., Zhang, J., 2012. Heterogeneous UV/Fenton degradation of TBBPA catalyzed by titanomagnetite: catalyst characterization, performance and degradation products. Water Res. 46, 4633-4644.

Zhu, B.Z., Shan, G.Q., 2009. Potential mechanism for pentachlorophenol-induced carcinogenicity: a novel mechanism for metal-independent production of hydroxyl radicals. Chem. Res. Toxicol. 22, 969-977.

Zhu, B.Z., Kitrossky, N., Chevion, M., 2000. Evidence for production of hydroxyl radicals by pentachlorophenol metabolites and hydrogen peroxide: a metal-independent organic Fenton reaction. Biochem. Biophys. Res. Commun. 270, 942-946.

Zhu, B.Z., Zhao, H.T., Kalyanaraman, B., Frei, B., 2002. Metal-independent production of hydroxyl radicals by chlorinated quinones and hydrogen peroxide: an ESR spin-trapping study. Free Radic. Biol. Med. 32, 465-473.

Zhu, B.Z., Zhao, H.T., Kalyanaraman, B., Liu, J., Shan, G.Q., Du, Y.G., Frei, B., 2007a. Mechanism of metal-independent decomposition of organic hydroperoxides and formation of alkoxyl radicals by halogenated quinones. Proc. Natl. Acad. Sci. U. S. A. 104, 3698-3702.

Zhu, B.Z., Kalyanaraman, B., Jiang, G.B., 2007b. Molecular mechanism for metal-independent production of hydroxyl radicals by hydrogen peroxide and halogenated quinones. Proc. Natl. Acad. Sci. U. S. A. 104, 17575-17578.

Zhu, B.Z., Shan, G.Q., Huang, C.H., Kalyanaraman, B., Mao, L., Du, Y.G., 2009. Metal-independent decomposition of hydroperoxides by halogenated quinones: detection and identification of a quinone ketoxy radical. Proc. Natl. Acad. Sci. U. S. A. 106, 11466-11471.

Zhu, B.Z., Zhu, J.G., Fan, R.M., Mao, L., 2011a. Metal-independent pathways of chlorinated phenol/quinone toxicity. Adv. Mol. Toxicol. 5, 1-43.

Zhu, B.Z., Fan, R.M., Qu, N., 2011b. A novel mechanism for metalindependent hydroxyl radical production by hydrogen peroxide and halogenated quinones. Mini-Rev. Org. Chem. 8, 434-437.

Zhu, B.Z., Mao, L., Huang, C.H., Qin, H., Fan, R.M., Kalyanaraman, B., Zhu, J.G., 2012. Unprecedented hydroxyl radical-dependent two-step chemiluminescence production by polyhalogenated quinoid carcinogens and $\mathrm{H}_{2} \mathrm{O}_{2}$. Proc. Natl. Acad. Sci. U. S. A. 109, 16046-16051.

Zimbron, J.A., Reardon, K.F., 2009. Fenton's oxidation of pentachlorophenol. Water Res. 43, 1831-1840. 